\title{
ROLE OF MARKET MICROSTRUCTURE IN THE RELATIONSHIP BETWEEN MARKET CO-MOVEMENT AND MARKET EFFICIENCY
}

\author{
XIAOFEI ZHANG \\ Master of Management, Wuhan University, 2008
}

\author{
A Thesis \\ Submitted to the School of Graduate Studies \\ of the University of Lethbridge \\ in Partial Fulfillment of the \\ Requirements for the Degree \\ MASTER OF SCIENCE IN MANAGEMENT \\ Faculty of Management \\ University of Lethbridge \\ LETHBRIDGE, ALBERTA, CANADA
}

(C) Xiaofei Zhang, 2012 


\begin{abstract}
This study examines the effects of changes in stock market microstructure on internal market efficiency and explores the relations among internal market efficiency, market co-movement and cross-market efficiency using evidence from Shanghai and Hong Kong stock exchanges. The results show that changes in the market microstructure have significant effects on the internal market efficiencies of the two markets. Second, the developed market (Hong Kong stock exchange) is not always more efficient than the emerging market (Shanghai stock exchange). Third, the cross-market efficiency is only affected by the internal market efficiency of the emerging market during normal economic conditions, but is determined by the internal market efficiency of the emerging market and the market co-movement during the financial crisis period. Finally, this study confirms Dwyer and Wallace's (1992) statement that strong market co-movement does not imply cross-market inefficiency.
\end{abstract}




\section{Acknowledgement}

I would like to give my sincere appreciation to my thesis co-supervisors, Dr. Ebenezer Asem and Dr. Rossitsa Yalamova for their insightful guidance and valuable comments during the completion of this study. Without Dr. Asem's scientific reasoning and Dr. Yalamova's mathematical skills, this study would not have been possible.

My thanks and appreciation also goes to my reader, Dr. Vishaal Baulkaran, for his patience and instruction over the course of this research. Dr. Baulkaran taught me how to write a formal and scientific thesis and helped me check the result of my research in a robust manner.

I would also like to thank Dr. Gary Tian and Dr. Helen Kelley for their service on my Examination Committee. I also want to thank my classmates Andy Xu, Anirban Kar, and Daniel Rutledge for their help.

Finally, I dedicate this thesis to my parents and fiancée for their support during my study. 


\section{Table of Contents}

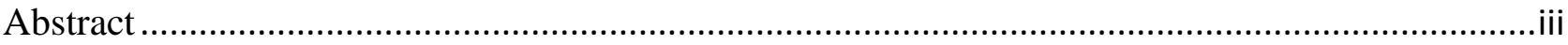

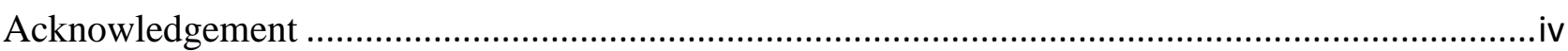

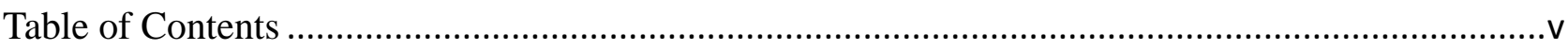

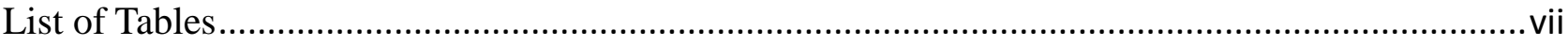

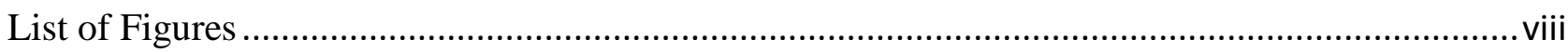

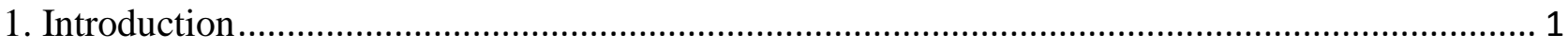

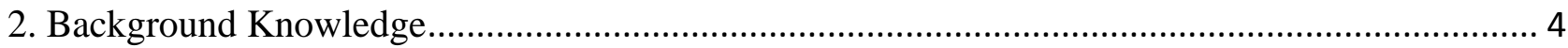

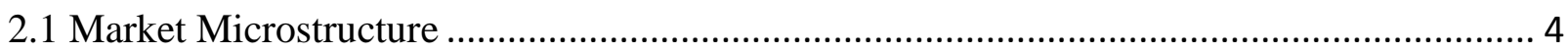

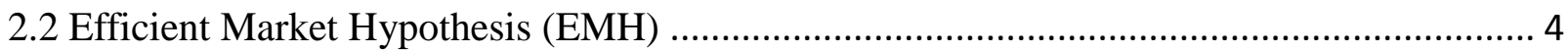

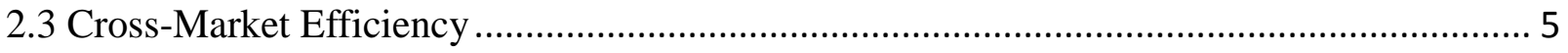

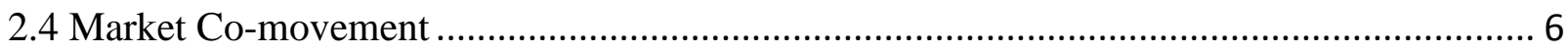

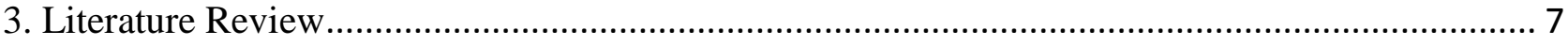

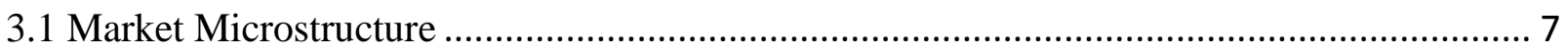

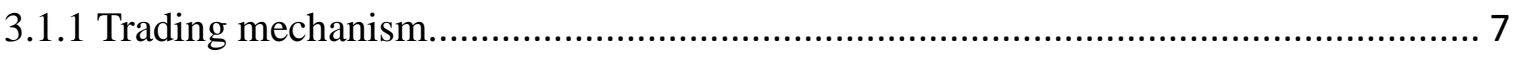

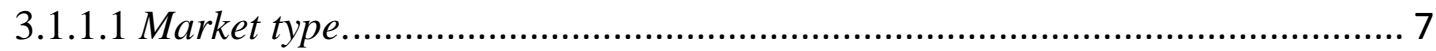

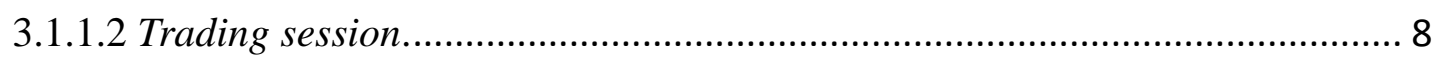

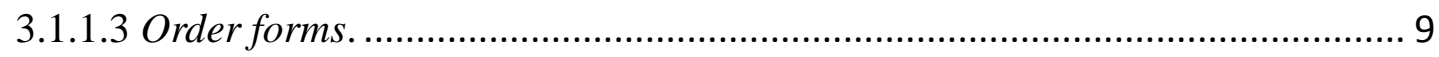

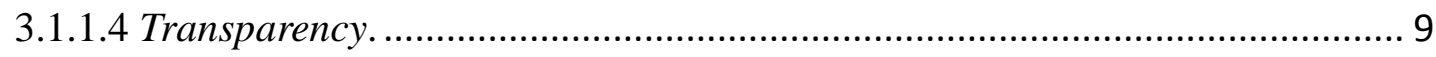

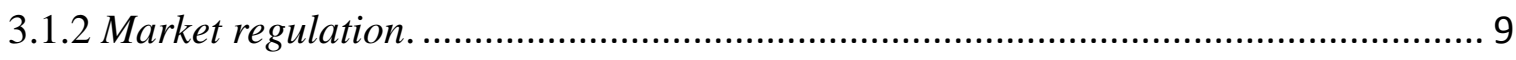

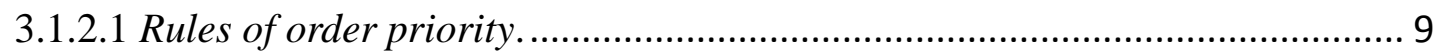

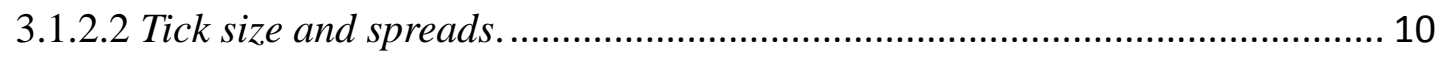

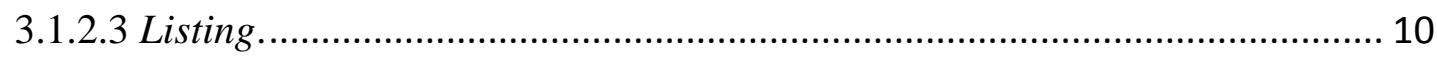

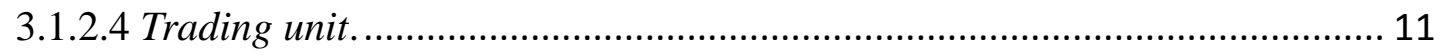

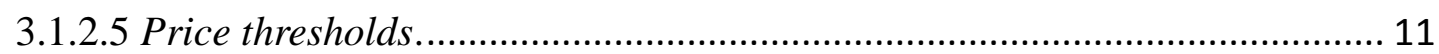

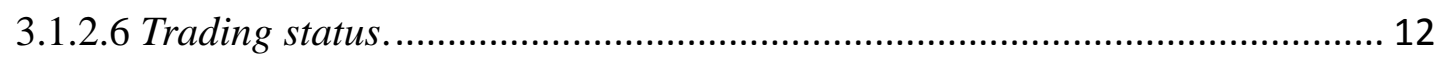

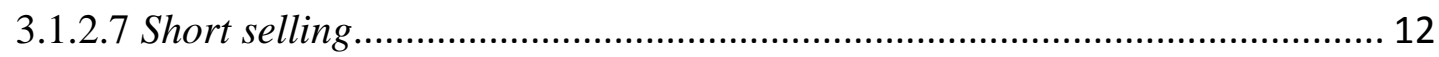

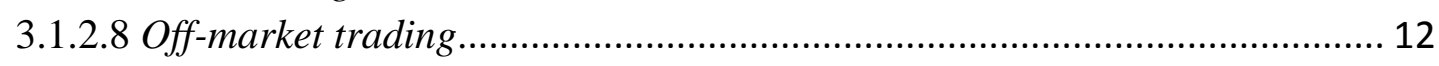

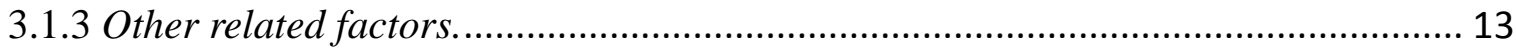

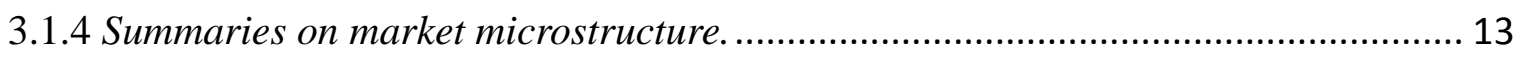

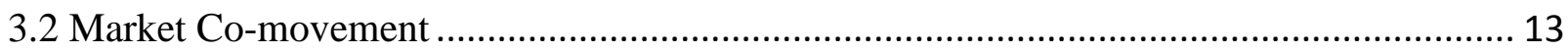

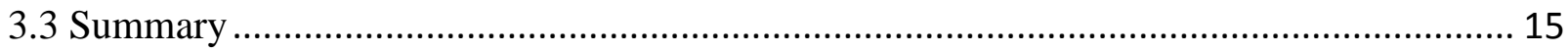

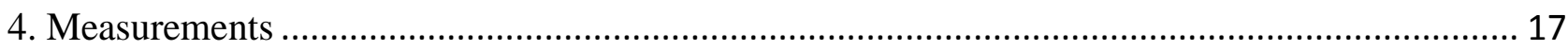

4.1 Measurement for Market Efficiency …................................................................... 17

4.1.1 Traditional measurement for market efficiency. ........................................................ 18

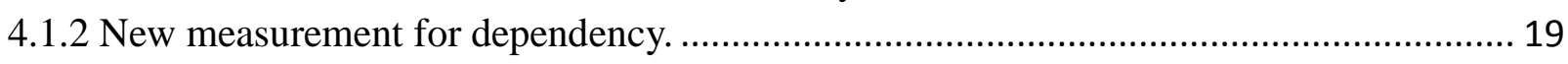

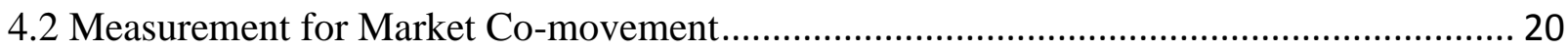

4.2.1 Traditional measurement for market co-movement............................................. 21

4.2.2 Wavelet measurements. .............................................................................. 22

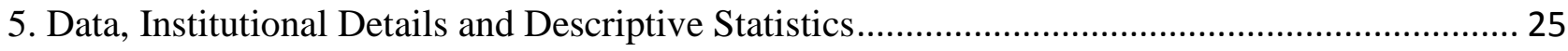

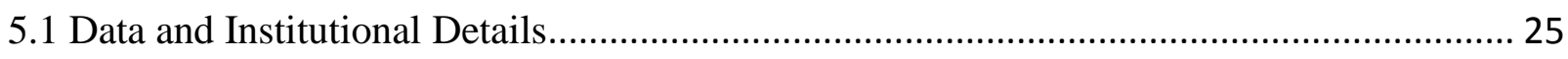

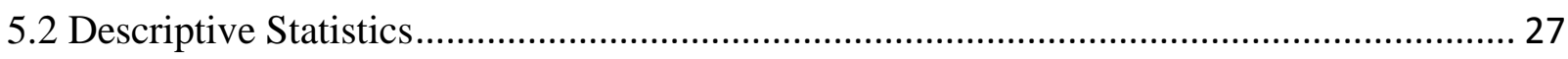

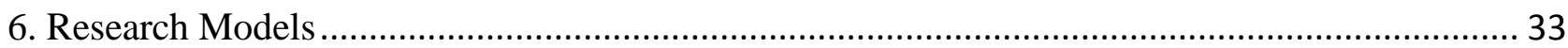

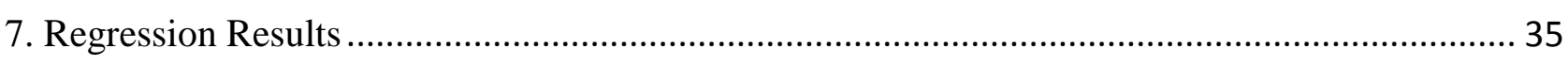




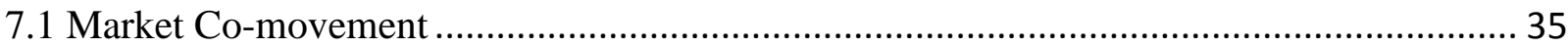

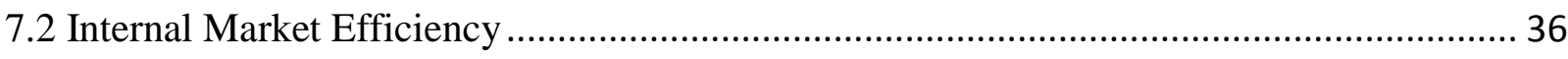

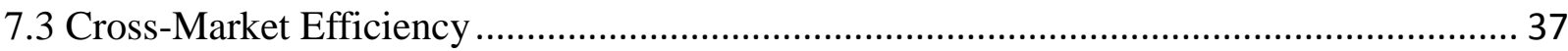

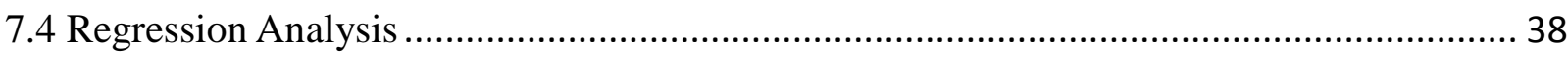

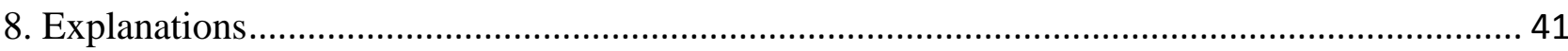

8.1 Period of Releasing Retained Common Shares in the Shanghai Exchange ......................... 41

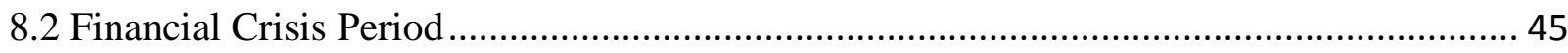

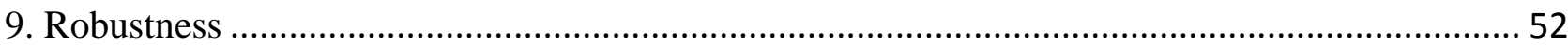

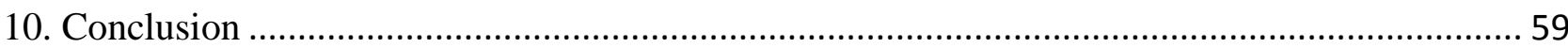

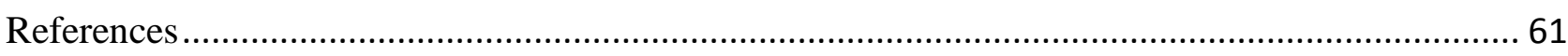




\section{List of Tables}

Table 1 Theoretical Effects of Sub-dimensions of Market Microstructure ............................... 14

Table 2 Differences of Status Quo of Market Microstructure in the Two Exchanges ................. 26

Table 3 Significant Events Related to Market Microstructure in both Equity Markets ............. 27

Table 4 Descriptive Statistics for Gross Returns in both Exchanges........................................ 29

Table 5 Paired Differences between Means of Daily Gross Returns ....................................... 30

Table 6 Differences of Means between Times Periods in Both Exchanges ............................... 31

Table 7 Differences of Variances between Time Periods in Both Exchanges ........................... 32

Table 8 Relationship among Market Co-Movement, Market Efficiency and Cross-Market

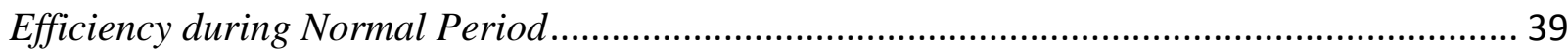

Table 9 Effect of the Change of the Market Microstructure during the Releasing Period ........ 43

Table 10 Relationship among Market Co-Movement, Market Efficiency and Cross-Market

Efficiency during the Releasing Period ............................................................................ 44

Table 11 Effect of the Change of the Market Microstructure during the Financial Crisis Period

Table 12 Relationship among Market Co-Movement, Market Efficiency and Cross-Market

Efficiency during the Financial Crisis Period

Table 13 Relationships among Market Co-movement, Internal Market Efficiency and

Cross-Market Efficiency Based on 60 Trading Days.

Table 14 Relationships among Market Co-movement, Internal Market Efficiency and

Cross-Market Efficiency Based on 120 Trading Days

Table 15 Relationships among Market Co-movement, Internal Market Efficiency and

Cross-Market Efficiency Based on Cross-Listing Indices ..... 56

Table 16 GMM Regressions for Relationship among Internal Market Efficiency, Market

Co-movement, and Cross-Market Efficiency 58 


\section{List of Figures}

Figure 1. Time Flow of Price Movement in Two Markets 1

Figure 2. Market Indices in the Shanghai Exchange and the Hong Kong Exchange ............... 28

Figure 3. Squared Wavelet Coherence for Market Co-movement.......................................... 36

Figure 4. Normalized Entropy for the Shanghai Exchange and Hong Kong Exchange............ 37

Figure 5. Normalized Mutual Information between the Two Markets ...................................... 38

Figure 6. Wavelet Coherence between the two Markets during the Leasing Period ................. 42

Figure 7. Normalized Entropy and Mutual Information in both Markets during the Releasing

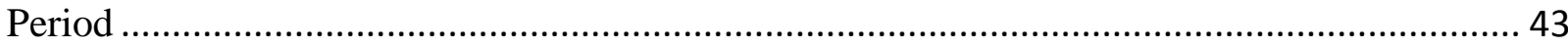

Figure 8. Wavelet Coherence between the two Markets during the Financial Crisis Period.... 46

Figure 9. Normalized Entropy and Mutual Information in both Markets during the Financial

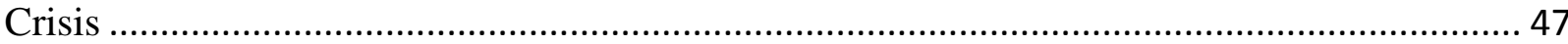

Figure 10. Wavelet Coherence between the two Markets based on Cross-Listing Indices ....... 55 


\section{Introduction}

The study of the co-movement patterns or correlation among international financial markets has drawn a great deal of interest from finance researchers. It has been established in prior literature that the correlations among international markets are time-varying and relatively strong in bearish and volatile market. Researchers, for instance Phylaktis and Xia (2009), attribute these characteristics to the globalization and integration of international markets. Understanding the correlation pattern is of interest to both scholars and investors since it plays a significant role in international portfolio diversification strategies. The underlying theory is that the weaker the correlation across markets, the greater the potential benefit of the international diversification strategy.

Previous studies reveal that the dynamic pattern of co-movement across international financial markets also plays an important role in understanding the relationship between internal market efficiency ${ }^{1}$ and cross-market efficiency ${ }^{2}$. However, these studies are based on index option markets or exchange rate markets and do not make the distinction between market co-movement and cross-market inefficiency. Following Dwyer and Wallace (1992), this study predicts that a strong market co-movement does not imply cross-market inefficiency.

Consider two markets ${ }^{3}$, home market ${ }^{4}$ and host market:

Home Market

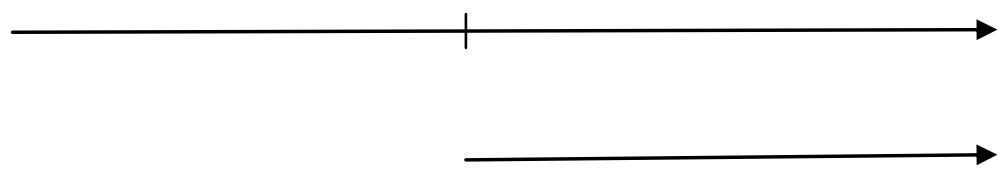

Host Market

Figure 1. Time Flow of Price Movement in Two Markets

\footnotetext{
${ }^{1}$ The concept of internal market efficiency refers to predicting future price movement based on current market information.

${ }^{2}$ The concept of cross-market efficiency relates to predicting future price movement based on current information in another market.

${ }^{3}$ The illustration is based on an ideal model, which assumes only two market conditions, namely efficient market and inefficient one. In practice, financial markets are inefficient and have different degrees of the internal market efficiency.

${ }^{4}$ This illustration, assumes the home market is the basis for analysis.
} 
if the home market is self-inefficient and the correlation between the home market and the host market is strong, the two markets are cross-market inefficient. In the home market, due to self-market inefficiency, the future return patterns can be predicted based on the past price movement in that market. Due to the strong co-movement, the future return in the host market could also be predicted. If the home market is self-inefficient, and the correlation is weak, the two markets are also cross-market efficient. In this case, although the future price is predictable in the home market, the future return patterns in the host market cannot be estimated based on historical market information in the home market because of the weak relationship between prices in both markets.

If the home market is self-efficient, then the two markets are cross-efficient even when the correlation of prices across markets is high. Since the price in the home market is efficient and is close to the Geometric Brownian Motion $(\mathrm{GBM})^{5}$, the future return in the home market cannot be estimated even with the market information in the host market.

Studies on international market co-movement generally have two empirical characteristics. First, the cross-correlation between two financial market composite indices is employed to investigate the pattern of co-movement (for example, Chiang, Tan, \& Li, 2007). Second, weekly or monthly returns data is used rather than daily or intraday data (for example, Phylaktis \& Xia, 2009; Rua \& Nunes, 2009).

Based on the idea that specific reforms of market have impacts on market microstructure (Lagorade-Segot, 2009), I suggest that, in addition to globalization, the development of market microstructure can partially explain the co-movement patterns between two financial markets since the trading rules and regulations determine how investors behave in the market. Assuming that the two markets are the same in all aspects except for the trading sessions, a high correlation could be

\footnotetext{
${ }^{5}$ In a Geometric Brownian Motion, the next value of a time series varies randomly from the current value.
} 
observed between market composite indices. In other words, the development of market microstructure affects the correlation pattern of index returns and therefore has an impact on the cross-market efficiency.

The main objectives of this study are to understand the dynamic nature of market co-movement based on the development of the market microstructure, as well as investigate its role on internal market efficiency and on the relationship between self-market efficiency and cross-market efficiency. Therefore, this study contributes to literature in the following ways: First, to my knowledge, this is the first study to examine the impact of market microstructure on internal market efficiency and cross-market efficiency. Second, since there is only limited literature on the difference between market co-movement (or integration) and cross-market inefficiency, this study aims to fill the gap in the literature. Finally, by using a novel methodology to investigate the impact of market microstructure from both time and frequency domains, investors will have a better understanding of the nature of the trading mechanism ${ }^{6}$ and the influence of changes in specific trading regulations.

This study is organized as follows. Section 2 provides an overview of several important concepts explored in this study. Previous research about the effects of market microstructure and market co-movement is reviewed in section 3. In section 4, I present the various measurements used in the analysis for internal market efficiency and market co-movement, followed by a data overview in section 5. Regression model is discussed in section 6, and the corresponding regression results are presented in section 7. The explanation and the robust check follow in section 8 and 9, while the conclusions are drawn in section 10.

\footnotetext{
${ }^{6}$ Trading mechanism refers to a set of trading rules that dominates transaction in the market.
} 


\section{Background Knowledge}

In this section, I provide an overview of several important concepts such as market microstructure, efficient market hypothesis, cross-market efficiency and market co-movement.

\subsection{Market Microstructure}

Market microstructure, defined by O'Hara (1995), is the research on how specific trading mechanisms affect investors' decision-making processes. Empirically, the study on market microstructure aims to answer the question of how the change of a specific trading rule affects the market efficiency and liquidity.

According to Madhavan (2000), studies on market microstructure can be classified into four categories. First, price formation and price discovery, which investigate how latent demands are translated into realized prices and volumes, including investigation of determinants of trading costs and processes of information incorporated into prices. Second, market structure and design issues, which concern the relationship between price formation processes and trading protocols. Third, information and disclosure, which assume that the behaviors of traders are affected by the "black box"7. Finally, informational issues arising from the interface of market microstructure with other areas of finance, such as corporate finance, asset pricing, and international finance.

Studies on market microstructure focus on the impact of changing trading rules or regulations in a single market, but pay little attention to the impact caused by a change of microstructure in one market to other related markets. This influence cannot be ignored because any market is not completely isolated from international financial markets, and also because of the tendency of globalization.

\subsection{Efficient Market Hypothesis (EMH)}

\footnotetext{
7 The "black box" here refers to situation in which investors have knowledge of their inputs (such as orders) and outputs (such as prices and volumes), but without any knowledge about the internal formation process.
} 
The Efficient Market Hypothesis, first defined by Fama (1970), refers to an efficient financial market in which price reflects all value related information (market, public, and private information) and in which the investor cannot always achieve excess returns. According to Fama, depending on the content of information that is incorporated in the current price, market efficiency can be categorized into three forms.

The first and weakest form is the weak-form efficiency, which means that historical data cannot be used to predict the future price movement. Therefore, under this form of market efficiency, the future price movement is entirely determined by the information which is not contained in the past price series, and technical analysis techniques are unable to generate excess returns consistently. The second form is semi-strong efficiency, which assumes that all public available information has already been incorporated in the current price. In other words, investors with public information cannot earn excess returns, and only the investors with private (inside) information can take advantage of the market under this form of market efficiency. This type of market assumes prices adjust to newly released information in a rapid and unbiased way. Compared to the weak form efficiency, under the semi-strong form, neither fundamental analysis nor technical analysis can generate excess returns. The final and strongest form of market efficiency is strong-form efficiency, which states that all available information (market, public, and private information) cannot be used to predict future price movement. Therefore, investors cannot earn excess returns regarding the information they retained.

\subsection{Cross-Market Efficiency}

Generally, the cross-market efficiency is investigated from the perspective of mispricing and based on the index option market or exchange rates market (Brunetti \& Torricelli, 2007; Kühl, 2010; Vipul, 2008). In this study, the cross-market efficiency, as a sub-concept of general market efficiency 
theory, is defined as the idea that the past price movement in one market cannot be used to predict the future price motion in another market since the current price has already incorporated all available value-related information.

\subsection{Market Co-movement}

Market co-movement refers to average cross-correlation or synchronicity, which is the fraction of stocks that move together at a given time (Morck et al., 2000). Empirically, co-movement between two financial markets is studied by analyzing the co-integration or cross-correlation between the two market composite indices. 


\section{Literature Review}

The literature related to this topic can be divided into two branches: studies on market microstructure and studies on market co-movement.

\subsection{Market Microstructure}

As suggested by Lagorade-Segot (2009), microstructures of emerging markets such as informational efficiency, volatility, and liquidity levels are affected by economic and political contexts of insider trading regulations, trading system automation, and accounting standardization. Additionally, he suggested that specific market reforms have different marginal impacts on market microstructure. However, in this study, I use market microstructure and trading rules of equity market interchangeably.

Based on the work of Asmar and Ahmad (2011), market microstructure can be analyzed from the two sub-dimensions of trading mechanism and market regulation.

3.1.1 Trading mechanism. The trading mechanism refers to the trading methods and can be studied in terms of market type, trading sessions, order forms and market transparency.

3.1.1.1 Market type. There are three dimensions of market type, including degree of continuity, role of market makers, and degree of automations. Since most of the financial markets around the world are hybrid ${ }^{8}$, involving market makers, brokers, dealers, and clearing house and electronic automation ${ }^{9}$, there is limited literature about the impacts of a change of market type.

Pagano and Schwartz (2003) investigated the effects of the introduction of electronic closing call auctions on market quality in Euronext Paris. They revealed that the new degree of continuity could lower the transaction costs and improve the market's ability of price discovery.

Chelley-Steeley (2008) examined the effects of the introduction of closing call auction at the

\footnotetext{
8 In a hybrid market the market combines call auction and continuous trading session together.

${ }^{9}$ The electronic automation is compared to the broker/dealer open cryout trading.
} 
London Stock Exchange in 2000. The examination concluded that after the effectiveness of the closing call auction, opening and closing market quality has improved and the greatest improvement was with the most inactive securities.

Comerton-Forde, Rydge, and Burridge (2007) investigated the impact of introducing of a new opening call auction on March 25, 2002 in the Hong Kong Exchange. Contrary to previous studies, they showed that there is a decrease in market quality after the introduction, which is measured in terms of price efficiency, price volatility, relative volumes and absolute spreads.

Similarly, Gerace, Tian, and Zheng (2009) compared the market liquidity before and after the introduction of a new pre-market call auction system on July 1, 2006 in the Shanghai Exchange. They concluded that after the increase of transparency during the opening call auction, there is an increase in participation during the auction and a reduction of orders placed in the continuous session, which results in lower price volatility and narrower proportional bid-ask spreads.

Moreover, Huang and Stoll (1996) compared the bid-ask spreads in dealer (quote-driven) markets and in auction (order-driven) markets, and showed that the auction market could lower the transaction costs for investors. In addition, Madhavan (1992) suggested that the dealer market could lower the volatility and improve the pricing efficiency in the market. In sum, markets with call auction and electronic systems generally improve the market quality.

3.1.1.2 Trading session. The trading session refers to the defined period time of trading by exchange authority. Asem (2007) examined the market volume of the NYSE when its trading hours were extended on September 30, 1985 and found that the volume declined initially, as predicted by closure models, but then gradually increased to its pre-extension levels. This result suggests that changing trading session has a temporary impact on investors' trading decision. 
Alexakis and Balios (2008) investigated the influence of change of microstructure in the Athens Stock Exchange. They concluded that the structure and duration of trading session have little effect on volatility and informational efficiency, and that continuous trading seems to be a more efficient regime than trading with halts. Generally, markets with halts ${ }^{10}$ are less efficient and a specific time period of trading has little impact on market quality.

3.1.1.3 Order forms. Orders represent the intent of trading (buying or selling) a listed security in a secondary market. Orders can take the form of market order, limit order, stop order, and other forms, which could control the price, quantity, and execution of trades.

Easley and O'Hara (1991) examined the effect of order forms on security prices. They suggested that the order forms affect the trading behavior of investors and further the price formation process. Harris and Hasbrouck (1996) compared the execution performance for market and limit orders, and revealed that the limit order commonly outperforms market order.

3.1.1.4 Transparency. Market transparency is the quality of the information observed regarding price formation processes by market participants. Generally, the information includes past and current prices, volumes, bid-ask spreads, quotes and identities of market participants. The previous research on the impact of transparency suggests that a high level of market efficiency or quality is associated with high levels of transparency (Chung \& Chuwonganant, 2009; Madhavan, Porter, \& Weaver, 2005; Pagano \& Roell, 1996).

3.1.2 Market regulation. Market regulation, defined as the rules about how to trade, can be analyzed from the perspectives of rules of order priority, tick size and spreads, listing, trading unit, price thresholds, trading status, shorting selling, and off-market trading (Asmar \& Ahmad, 2011).

3.1.2.1 Rules of order priority. Order priority refers to how orders are matched in the

\footnotetext{
${ }^{10}$ The halt refers to the break between morning and afternoon trading sessions.
} 
market. Generally, orders are prioritized by price first and then by time. Demarchi and Foucault (2000) suggested that the choice of secondary priority is important to encourage traders to provide liquidity, and time priority as the secondary priority could give incentives for price competition among traders.

3.1.2.2 Tick size and spreads. Tick size refers to the minimum change on the price. Generally, the tick size can be in decimals or fractions and also can be varied or fixed within different price ranges. Ascioglu, Comerton-Forde, and McInish (2010) examined the different tick sizes in the Tokyo Stock Exchange, which are based on stock prices solely. They suggested that the tick size should be determined by trading activity and stock price, and posited that transaction costs would be unnecessarily high if the minimum tick size is set inadequately.

Hsieh, Chuang, and Lin (2008) examined the impact of tick size reduction in Taiwan Stock Exchange. They showed that this change of market microstructure reduced bid-ask spread, market depth, market liquidity, and binding-constraint probability, which led to improvement in market efficiency and reduction in trading costs in the market. Similarly, many other researchers have investigated the impact of reduction of tick size in different stock exchanges and have come to similar conclusions. For example, Alampieski and Lepone (2009) studied the change of tick size in the Sydney Stock Exchange, Kurov (2008) tested the effect of tick size reduction in the Chicago Mercantile Exchange (CME), and Pavabutr and Prangwattananon (2008) made their investigation based on the Thailand Stock Exchange. In sum, the smaller the tick size, the smaller transaction cost incurred during trading and thus the higher the market quality.

3.1.2.3 Listing. The rules of listing refer to the requirements imposed by the exchange authority to the individual company for being listed in the secondary market. Generally, less strict 
rules result in more unfair trades, which harm investors and lead to deterioration of the market efficiency. On the other hand, more strict rules result in a healthier trading environment and thus more participants in the market, which leads to a higher level of market efficiency.

3.1.2.4 Trading unit. In an exchange, securities are generally traded on the basis of a standardized quantity, usually 100 shares. However, odd-lot trading is also available in some exchanges to meet the specific requirement of an individual investor.

Amuhud, Mendelson, and Uno (1999) investigated the impact of "round lots" in the Japanese Equity Market. Their investigation suggested that the reduction in minimum trading units could increase the number of individual investors, stock liquidity, and stock prices. Moreover, Hauser and Lauterbach (2003) reached a similar conclusion based on their research on the Tel-Aviv Stock Exchange. Practically, lower trading units will result in reduced transaction costs and more efficiency in the market pricing process.

3.1.2.5 Price thresholds. Price thresholds provide information about the price ranges that securities can be traded based on the last closing price. Practically, a price threshold will limit the market's ability to reflect on the newly released information.

Ryoo and Graham (2002) examined the market efficiency of the Korean stock market, where five regimes of daily price limits are employed. They found a positive relationship between daily price limits and the proportion of stock price movement in a random walk. In other words, as the daily price limits increase, the stock price is more efficient.

Chan, Kim, and Rhee (2005) investigated the impact of wide price limits in the Kuala Lumpur Stock Exchange from the perspectives of information asymmetry, arrival rates of informed traders, and order imbalance. They concluded that the price threshold has no positive effect on those 
perspectives, and suggested that price thresholds helped to improve price discovery and generated high transaction costs.

3.1.2.6 Trading status. In the case of news announcements or corrections of order imbalance the exchange authority may suspend the trading of a security. The implementation of the rules of trading status gives investors fair opportunities to reflect on the new information and could improve the market efficiency.

3.1.2.7 Short selling. Short selling refers to the sale of securities in the market, which are borrowed from a third party, and brought back at a future date to return them to the borrower. This trading strategy is applied when the investor predicts that the price will decline in the future. Generally, the market that allows short selling is more efficient than the market that forbids short selling. In the former market, investors can earn excess returns when prices are increasing and declining, which makes the price in the market close to the intrinsic value.

Boehmer, Jones, and Zhang (2008) suggested that short sellers are important for efficient stock prices. Boehmer and $\mathrm{Wu}$ (2009) suggested that greater shorting flow reduces deviations of transaction prices from a random walk, and accelerates the incorporation of public information into prices. In other words, short selling could be helpful to discover the efficient price of stocks. Therefore, the less short sale restriction there is, the more market informational efficiency, and vice versa.

3.1.2.8 Off-market trading. Off-market trading refers to the trade of listed securities outside the formal exchange. The use of off-market trading is to remove the impact of trading large blocks of shares on market price. For example, Booth et al. (2002) suggested that upstairs traders (off-market traders) are associated with less information content and limited influence on price. 
3.1.3 Other related factors. In addition to the theoretical framework suggested by Asmar and Ahmad (2011), it can be argued that the rules about settlement system, friction, and sources of capital also have an impact on market microstructure.

Generally, if investors have to wait a long time to sell their inventory, they lack the ability to reflect on newly released information in a rapid way, which could result in the deterioration of market efficiency. In addition, the high friction of trading such as the high commission and stamp duty will reduce the incentive for investors to reflect on the new information, resulting in a less efficient market compared to a market with low trading friction.

In terms of the sources of capital, a market in which both domestic and foreign investors can trade listed securities could provide heterogeneous opinions and increase the participation in the market. This participation may result in an improved market efficiency compared to a market where only domestic investors could participate.

3.1.4 Summaries on market microstructure. To sum up, the theoretical effects of sub-dimensions of market microstructure on market efficiency suggested by previous literatures are summarized in Table 1.

\subsection{Market Co-movement}

Generally, the study on market co-movement is based on a series of low-frequency data (daily or longer time period data) and market composite indices rather than high-frequency data (intraday data) and individual stock price.

Rua and Nunes (2009) investigated the cross-country co-movement patterns of four developed countries (Japan, Germany, UK, and US) from both time and frequency domains on the basis of market price index, as well as for the ten economic sectors that make up the index. By using wavelet analysis, they revealed that the co-movement pattern between all pairs of these four countries 
is not constant over different periods of time.

Table 1 Theoretical Effects of Sub-dimensions of Market Microstructure

\begin{tabular}{|c|c|c|c|}
\hline \multicolumn{2}{|c|}{ Market Microstructure } & $\begin{array}{c}\text { High Level of Market } \\
\text { Efficiency }\end{array}$ & $\begin{array}{c}\text { Low Level of Market } \\
\text { Efficiency }\end{array}$ \\
\hline \multirow{7}{*}{$\begin{array}{c}\text { Trading } \\
\text { Mechanism }\end{array}$} & \multirow{5}{*}{ 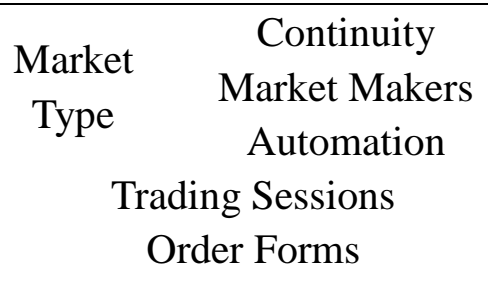 } & With call auction & Without call auction \\
\hline & & Dealer Market & Auction \\
\hline & & Electronic & Cryout \\
\hline & & Without Halt & With Halt \\
\hline & & Limit Order & Market Order \\
\hline & \multirow{2}{*}{ Transparency } & High Level of & Low Level of \\
\hline & & Transparency & Transparency \\
\hline \multirow{7}{*}{$\begin{array}{c}\text { Market } \\
\text { Regulation }\end{array}$} & Order Priority & Price/Time & Other Priority \\
\hline & Tick Size & Lower & Higher \\
\hline & Listing & More Strict & More Loosen \\
\hline & Trading Unit & Lower & Higher \\
\hline & Price Thresholds & No Thresholds & With Thresholds \\
\hline & Trading Status & With Implementation & $\begin{array}{l}\text { Without } \\
\text { Imnlementation }\end{array}$ \\
\hline & Shorting Selling & Available & Forbidden \\
\hline \multirow{3}{*}{$\begin{array}{c}\text { Other Related } \\
\text { Rules }\end{array}$} & Settlement System & Less Time Interval & More Time Interval \\
\hline & $\begin{array}{l}\text { Commission \& } \\
\text { Stamp Duty }\end{array}$ & Lower & Higher \\
\hline & Main Capital Source & Multi-Sources & Single-Source \\
\hline
\end{tabular}

Chiang, Tan, and Li (2007) studied the dynamic correlations of daily stock returns by using Chinese A-share and B-share composite indices in both the Shanghai and Shenzhen exchanges. They concluded that the correlation coefficient is time-varying and is affected by restrictions and trading activities. Aslanidis, Osborn, and Sensier (2009) presented similar results investigating the STCC (Smooth Transition Conditional Correlation) using monthly data of the Standard \& Poor composite index (S\&P) and the Financial Times All Share Index (FT).

In their article, Brockman, Liebenberg, and Schutte (2010) suggested that the amount of information production is negatively correlated to market co-movement. In other words, if 
information production is ample, the co-movement is low, and vice versa.

Phylaktis and Xia (2009) investigated the contagion effect ${ }^{11}$ from the perspective of asset pricing at the sector level. They suggested that the integration between sectors is time-varying, heterogeneous, and that some of the markets are isolated from international markets during crisis periods.

Brooks and Negro (2006) showed that a company's global nature is positively related to its exposure to global shocks and negatively related to its exposure to country shocks.

Beine, Cosma, and Vermeulen (2010) revealed that stock market co-movement across return distribution is affected by macroeconomic variables asymmetrically. To be specific, global trading increases co-movement across the return distribution, "financial liberalization increases left tail co-movement" (Beine et al., 2010, p. 184) but has a minor impact on right tail, and "exchange rate volatility has a strong positive impact on lower tail co-movement” (Beine et al., 2010, p.191).

Bodart and Reding (1999) focused on the impact of the exchange rate regime on the correlation between time-varying stock market volatilities. Their analysis showed that an increase in exchange rate volatility was accompanied by a decline in international correlations. On the other hand, Kanas (2002) investigated whether the volatility of exchange rates was affected by the volatility of stock market returns for the US, UK, and Japan. The evidence presented suggested that the volatility of the home countries' stock returns was a determinant of exchange rate volatility for all three countries.

\subsection{Summary}

To my knowledge, there is limited literature on the relationship between market microstructure and market co-movement. In this study, I hypothesize that similar market

\footnotetext{
${ }^{11}$ The contagion effect is defined as the correlation over and above one would expect from economic fundamentals.
} 
microstructures will result in similar investment decisions made by trading participants, which leads to strong market co-movement and high correlation among the markets.

Additionally, to distinguish the two concepts of market co-movement and cross-market efficiency, this study hypothesizes that the cross-market efficiency is partially determined by the market co-movement and partially by self-market efficiency. 


\section{Measurements}

Traditionally, the measurements on market efficiency and market co-movement are established solely from frequency domain, which do not take into account the difference between short-term and long-term investment horizons (Rua \& Nunes, 2010). Naturally, investors with short-term interests are more interested in high frequency dependency and short horizon co-movement, whereas the long-horizon investors are more interested in low frequency information and long horizon correlations.

Additionally, cross-market efficiency and market co-movement are often used interchangeably. However, there is a need to clarify the difference between these two concepts. The concept of co-movement differs from the cross-market efficiency because the former concept emphasizes simultaneous price movements, while the latter analyzes the dependency pattern by considering the time sequence of price movements in the two markets. Therefore, using co-movement measurements to investigate the cross-market efficiency fundamentally ignores the property of time sequence, which should be included when considering the issue of market efficiency.

\subsection{Measurement for Market Efficiency}

The goal of measuring price efficiency is to detect the dependency of price series. If the price significantly correlates to its previous movement, the stock lacks efficiency since the investor could use the previous price movement to predict its following performance. On the other hand, if the relationship is insignificant, the stock is market efficient because investors cannot use the available market information to predict the following price movement. The researchers (e.g., Boehmer \& Wu, 2009; Hasbrouck, 1993; Wu, 2009) suggested using abnormal returns or gross returns to detect potential dependency within time series. 
This section includes a review of the traditional measurements (which investigate the market efficiency and market co-movement solely from frequency domain) and illustrates the measurements of Boltzmann-Gibbs-Shannon (BGS) entropy, corresponding normalized entropy, and mutual information. In this study, these measurements will be used as the measurements of market efficiency.

4.1.1 Traditional measurement for market efficiency. The simplest way to examine price efficiency is to use the Autoregressive model (AR model), to discover to what extent the current price could be explained by previous price series.

An autoregressive model with order $p$ could be defined as:

$$
A R(p)=X_{t}=c+\sum_{i=1}^{p} \varphi_{i} X_{t-i}+\varepsilon_{t}
$$

Where $\varphi_{1}, \ldots, \varphi_{p}$ are the parameters of the model, $c$ is a constant and $\varepsilon_{t}$ is the white noise, which has zero mean and constant variance $\sigma_{\varepsilon}^{2}$. A challenge to this model is that, generally, the variance of residual is varying over time, which is contrary to the assumption of this model.

As a result, the Autoregressive Conditional Heteroskedasticity (ARCH) model is introduced to overcome this drawback of the AR model. The ARCH model assumes that the variance of the residual at time point $t$ is a function of previous time period's residual. In its mathematical form, $\varepsilon_{t}=\sigma_{t} z_{t}$ and $\sigma_{t}^{2}=\alpha_{0}+\sum_{i=1}^{q} \alpha_{i} \varepsilon_{t-i}^{2}$. The distribution has a mean of zero and standard deviation of one, and $\alpha_{i} \geq 0, i \geq 0$.

As suggested by Engle (1982), the procedure of estimating the ARCH(p) model is to estimate the parameters from $\mathrm{AR}(\mathrm{p}) y_{t}=\alpha_{0}+\sum_{i=1}^{p} \alpha_{i} y_{t-i}+\varepsilon_{t}$ first, then obtain the parameters from the model of $\hat{\varepsilon}_{t}^{2}=\widehat{\alpha_{0}}+\sum_{i=1}^{q} \widehat{\alpha}_{l} \hat{\varepsilon}_{t-i}^{2}$, and finally test the null hypothesis that $\alpha_{i}$ for all $i=0, \ldots, p$ are equal to zero based on Chi-square distribution. 
However, the ARCH model cannot solve the problem when the variance $\sigma_{t}^{2}$ is also related to its previous variances $\sigma_{t-1}^{2}, \ldots, \sigma_{t-p}^{2}$. In this case, the Generalized Autoregressive Conditional Hereroskedasticity $(\mathrm{GARCH})$ model is employed. The $\operatorname{GARCH}(\mathrm{p}, \mathrm{q})$ takes the form of $\sigma_{t}^{2}=\alpha_{0}+$ $\sum_{i=1}^{q} \alpha_{i} \varepsilon_{t-i}^{2}+\sum_{i=1}^{p} \beta_{i} \sigma_{t-i}^{2}$. In this case, $\mathrm{p}$ is the order of the GARCH terms $\sigma^{2}$ and $\mathrm{q}$ is the order of the ARCH terms $\varepsilon^{2}$.

Despite the measurement's focus on the dependency of time series, the ability to adjust to the efficient price can also be used as a dimension of price efficiency. Hou and Moskowitz (2005) suggested price delays ${ }^{12}$ as a good estimate of market efficiency in this respect. This measurement captures the portion of individual stock return variation, which is explained by lagged market returns. The larger the delay, the less efficient the stock price is because it takes longer for the stock to adjust to the efficient price.

4.1.2 New measurement for dependency. Several researchers (for example, Darbellay \& Wuertz,2000; Gulko,1999) suggested using the Boltzmann-Gibbs- Shannon (BGS) Entropy to examine the degree of market efficiency. The investor, as an information receiver, can use entropy as a measurement of uncertainty about the future information received (Brissaud, 2005). In other words, the entropy could be seen as a measurement of randomness of the future price (return) movement. Given a continuous random variable $\boldsymbol{X}$ with its corresponding probability density function of $\boldsymbol{f}_{X}$, the BGS entropy is defined as $\boldsymbol{h}(\boldsymbol{X})=-\int \boldsymbol{f}_{\boldsymbol{X}}(\boldsymbol{x}) \boldsymbol{l o g} \boldsymbol{f}_{\boldsymbol{X}}(\boldsymbol{x}) \boldsymbol{d x}$. In its discrete version, the entropy is defined as $h(X)=-\sum f_{X}(x) \log \left(f_{X}(x)\right)$. Theoretically, the higher the value of calculated value of entropy, based on the price or return series, the more efficient the market, and vice versa.

Cross-market efficiency focuses on the dependency of two sets of price time series in two

\footnotetext{
12 Price delays refer to the speed of adjustment to market-wide information.
} 
different exchanges. If the current price movement in one exchange heavily depends on the previous price movement in another exchange, the two exchanges are cross-inefficient. On the other hand, if the current price motion in one exchange is independent with the previous price movement in the other exchange, the two exchanges are in state of cross-market efficiency.

Additionally, one can also employ the normalized entropy, which is defined as $\mathrm{n} h(X)=$ $-\int f_{X}(x) \log f_{X}(x) d x / \log (n)$, or $\mathrm{n} h(X)=-\sum f_{X}(x) \log \left(f_{X}(x)\right) / \log (n)$, to compare the degree of market efficiency in different markets (Pele \& Tupus, 2011). The $\mathrm{n}$ is the number of observations when calculating the entropy, and the base for the logarithm is 2 .

Darbellay and Wuertz (2000) also demonstrated how to use mutual information as a measurement to examine the dependency between two sets of time series. Hence, given continuous random variables $X$ and $Y$, their corresponding probability densities $f_{X}$ and $f_{Y}$, and the joint probability density of $f_{X, Y}$, the joint entropy can be defined as $h(X, Y)=-\iint f_{X, Y}(x, y) \log f_{X, Y}(x, y) d x d y$, and the mutual information is defined as $I(X ; Y)=$ $h(X)+h(Y)-h(X, Y)$

$=\iint f_{X, Y}(x, y) \log \frac{f_{X, Y}(x, y)}{f_{X}(x) f_{Y}(y)} \mathrm{dx} d y$, and its corresponding discrete version is $I(X ; Y)=h(X)+$ $h(Y)-h(X, Y)=\sum \sum f_{X, Y}(x, y) \log \frac{f_{X, Y}(x, y)}{f_{X}(x) f_{Y}(y)}$. The value of the mutual information is determined by the calculated entropy of time series of $X$ and $Y$. Theoretically, the mutual information $I(X ; Y)$ equals zero if and only if the two sets of time series are independent.

However, since the entropy is an increasing function with the length of a window (Brissaud, 2005), the choice of the rolling window length is important for comparing market efficiencies in different markets.

\subsection{Measurement for Market Co-movement}

The essence of market co-movement is the degree to which the market indices move together 
over time. Therefore, a high absolute value of the measurement (for example, Pearson's Correlation Coefficient) indicates a strong co-movement pattern, whereas a measurement close to zero indicates a weak co-movement over time. This section introduces the technique of wavelet, which serves as the measurement of market co-movement in this study, after revisiting the traditional measurements.

4.2.1 Traditional measurement for market co-movement. The most popular and simplest method for computing correlation coefficients is constant- correlation model. This model assumes that the correlation coefficient is constant over time. The calculation is given by $\rho_{X, Y}=\frac{\sum_{t=1}^{T}\left(r_{x, t}-\mu_{X}\right)\left(r_{Y, t}-\mu_{Y}\right)}{\sqrt{\sum_{t=1}^{T}\left(r_{x, t}-\mu_{X}\right)^{2} \sum_{t=1}^{T}\left(r_{Y, t}-\mu_{Y}\right)^{2}}}$, where $\mathbf{r}_{\mathbf{x}, \mathbf{t}}$ is the return for underlying asset $\mathrm{X}$ at time $t$ and $\mathbf{r}_{\mathbf{Y}, \mathbf{t}}$ is the returns for underlying asset $\mathrm{Y}$ at time $t$, while $\boldsymbol{\mu}_{\mathrm{X}}$ and $\boldsymbol{\mu}_{\mathrm{Y}}$ are the mean returns for $\mathrm{X}$ and $\mathrm{Y}$ assets over the whole sample period respectively.

The drawback of this method is that it assumes that the correlation of two sets of time series is constant over the study period, when in fact, dynamic relations in stock markets are often observed due to continual changes.

After considering the issue of time-varying conditions of the market, the Rolling Correlation Model is introduced. The Rolling Correlation Model is a simple approach to estimating the time-varying correlation by moving a fixed window length of the sample ahead by adding a new observation and dropping the most distant observation. The correlation is $\rho_{X Y, t m}=\frac{\operatorname{Cov}\left(r_{X, t m}, r_{Y, t m}\right)}{\sqrt{\operatorname{Var}\left(r_{X, t m}\right)} \sqrt{\operatorname{Var}\left(r_{Y, t m}\right)}}$, where $r_{X, t m}$ and $r_{Y, t m}$ are the return for underlying asset $X$ and $Y$ at time $t$ respectively, $\operatorname{Cov}\left(r_{X, t m}, r_{Y, t m}\right)$ is the covariance between these two underlying assets and $\operatorname{Var}\left(r_{X, t m}\right)$ and $\operatorname{Var}\left(r_{Y, t m}\right)$ are the corresponding variances which are based on a window length of $m$ days instead of based on the whole sample period.

The advantage of this model is that it is simple and easy to estimate; the main drawback is that 
the choice of window length may be arbitrary. Furthermore, the estimation of the correlation is derived from conditional covariances and variances. These conditional moments have been smoothed out by using a moving average.

4.2.2 Wavelet measurements. The wavelet transform decomposes a time series in terms of some elementary functions, the daughter wavelets or simply wavelets $\boldsymbol{\psi}_{\tau, \boldsymbol{s}}(\boldsymbol{t})$. Wavelets are 'small waves' that grow and decay in a limited time period. These wavelets result from a mother wavelet $\boldsymbol{\psi}(\boldsymbol{t})$, that can be expressed as function of the time position $\boldsymbol{\tau}$ (translation parameter) and the scale $\boldsymbol{s}$ (dilation parameter), which is related with the frequency. While the Fourier transform decomposes the time series into infinite length sines and cosines, discarding all time-localization information, the basic functions of the wavelet transform are shifted and scaled versions of the time-localized mother wavelet. More explicitly, wavelets are defined as $\boldsymbol{\psi}_{\tau, s}(\boldsymbol{t})=\frac{\mathbf{1}}{\sqrt{s}} \boldsymbol{\psi}\left(\frac{\boldsymbol{t}-\boldsymbol{\tau}}{\boldsymbol{s}}\right)$, where $\frac{1}{\sqrt{s}}$ is a normalization factor to ensure wavelet transforms are comparable across scales and time series.

To be a mother wavelet, $\psi(t)$ must fulfill the following three conditions: Zero mean: $\int_{-\infty}^{+\infty} \psi(t) \mathrm{d} t=0$; Square integrates to unity: $\int_{-\infty}^{+\infty} \psi^{2}(t) \mathrm{d} t=1$, which means that $\psi(t)$ is limited to an interval of time; and Admissibility condition: $0<C_{\psi}=\int_{0}^{+\infty} \frac{|\widehat{\psi}(\omega)|^{2}}{\omega} d \omega<+\infty$ where $\hat{\psi}(\omega)$ is the Fourier transform of $\psi(\mathrm{t})$, that is $\hat{\psi}(\omega)=\int_{-\infty}^{+\infty} \psi(t) e^{-i \omega \tau} d t$. This condition allows the reconstruction of a time series $x(t)$ from its continuous wavelet transform $W_{X}(\tau, s)$. Thus, it is possible to recover $x(t)$ from its wavelet transform through the following formula $x(t)=$ $\frac{1}{C_{\psi}} \int_{-\infty}^{+\infty}\left[\int_{-\infty}^{+\infty} \frac{1}{\sqrt{s}} \psi\left(\frac{t-\tau}{s}\right) W_{X}(\tau, s) d \tau\right] \frac{d s}{s^{2}}$.

Generally, the wavelet transform could be divided into the following two categories. The continuous wavelet transform of a time series $x(t)$ with respect to $\psi(t)$ is given by $W_{X}(\tau, s)=$ 
$\int_{-\infty}^{+\infty} x(t) \psi_{\tau, s}^{*}(t) d t=\frac{1}{\sqrt{s}} \int_{-\infty}^{+\infty} x(t) \psi^{*}\left(\frac{t-\tau}{s}\right) d t$, where $*$ denotes the complex conjugate. The second one is the discrete transform, in which the discrete time series $x(t), t=1, \ldots, N$, could be repressed by $W_{X}(\tau, s)=\frac{1}{\sqrt{s}} \sum_{t=1}^{N} x(t) \psi^{*}\left(\frac{t-\tau}{s}\right)$.

Although the most commonly used mother wavelet is the Morlet wavelet, several scholars have suggested that the filter Daubechies (db) with scale of 4 to 8 is a good choice in financial data analyzing (Crowley, 2005; Gençay, Selçuk, \& Whitcher, 2003, 2005; Helder \& Jin, 2007; Masset, 2008; Nielsen \& Frederiksen, 2005; Subbotin, 2008).

Following Maraum and Kurths (2004), given two time series $x(t)$ and $y(t)$, with wavelet transforms $W_{x}(\tau, s)$ and $W_{y}(\tau, s)$, one can define the cross-wavelet spectrum as $W_{x y}(\tau, s)=$ $W_{x}(\tau, s) W^{*}{ }_{y}(\tau, s)$, and wavelet power spectrum for time series $x(t)$ as $W_{x}(\tau, s)=W_{x}(\tau, s) W^{*}{ }_{x}(\tau, s)$

The wavelet coherency of these two sets of time series could be defined as the absolute value squared of the smoothed cross-wavelet spectrum, normalized by the smoothed wavelet power spectra (the product of two wavelet spectra) $R^{2}(\tau, s)=\frac{\left.\mid W_{x y}(\tau, s)\right) \mid}{\sqrt{W_{x}(\tau, s) W_{y}(\tau, s)}}$.

In a similar fashion, suggested by Torrence and Webster (1998), the wavelet squared coherency also would be defined as $R^{2}(\tau, s)=\frac{\left|S\left(s^{-1} W_{x y}(\tau, s)\right)\right|^{2}}{S\left(s^{-1}\left|W_{x}(\tau, s)\right|^{2}\right) S\left(s^{-1}\left|W_{y}(\tau, s)\right|^{2}\right)}$, where $S($.$) is a$ smoothing operator and could be written as $S(W)=S_{\text {scale }}\left(S_{\text {time }}\left(W_{n}(s)\right)\right)$, where $S_{\text {scale }}$ denotes smoothing along the wavelet scale axis and $S_{\text {time }}$ smoothing in time. For the case of Morlet wavelet, suitable smoothing operators are given by Torrence and Compo (1998), $\left.S_{\text {time }}(W)\right|_{s}=\left(W_{n}(s) *\right.$ $\left.c_{1}^{-t^{2} / 2 s^{2}}\right)\left.\right|_{s}$ and $\left.S_{s c a l e}(W)\right|_{n}=\left.\left(W_{n}(s) * c_{2} \Pi(0.6 s)\right)\right|_{n}$. Where $c_{1}$ and $c_{2}$ are normalization constants and $\Pi$ is the rectangle function. The factor of 0.6 is the empirically determined scale 
decorrelation length for the Morlet wavelet. In practice both convolutions are done discretely and therefore the normalization coefficients are determined numerically.

The squared wavelet coherency coefficient is in the range $0 \leq R^{2}(\tau, s) \leq 1$. Values close to zero indicate weak correlation, while values close to one provide the evidence of strong correlation. Therefore, one can use the squared wavelet coherency to measure the extent to which two time series move together over time and across frequencies. 


\section{Data, Institutional Details and Descriptive Statistics}

\subsection{Data and Institutional Details}

The Shanghai Stock Exchange and the Hong Kong Exchange are selected for the following reasons. First, the Shanghai Exchange is an emerging market and the Hong Kong Exchange is considered as a developed market and thus enhances our understanding of how these two kinds of markets co-move over time. Second, the Shanghai Exchange and the Hong Kong Exchange are under the same jurisdiction of the Chinese government, which is a unique characteristic compared to the previous study on the co-movement of developed market and emerging market (Christofferson et al., 2011; Rua \& Nunes, 2010).

Regarding market co-movement and market efficiency, the daily opening and closing prices of market composite index for the time period from January 4, 2000 to October 20, 2010 were obtained from Wind Information Corporation, Ltd. After removing the unmatched trading data due to statutory holidays, there are 2518 pairs of observations.

Based on the previous research and the information from the webpages of the two exchanges, the differences between the Shanghai Stock Exchange and the Hong Kong Exchange are listed in Table 2.

As outlined in the table, it is obvious that the two exchanges are similar in trading mechanisms except for the existence of market makers, whereas they are significantly different in the cases of market regulation and other related rules.

Amendments to the trading rules have been obtained from the webpage of each exchange ${ }^{13}$, which help delineate the development of the market microstructure. The effective date of new trading

\footnotetext{
${ }^{13}$ The webpages for the Hong Kong Exchange and the Shanghai Stock Exchange are http://www.hkex.com.hk and http://www.sse.com.cn/, respectively.
} 
rules, and content of changes in both exchanges are listed in Table 3.

Table 2 Differences of Status Quo of Market Microstructure in the Two Exchanges

\begin{tabular}{|c|c|c|c|c|}
\hline \multicolumn{3}{|c|}{ Market Microstructure } & Shanghai Exchanges & Hong Kong Exchange \\
\hline \multirow{7}{*}{$\begin{array}{c}\text { Trading } \\
\text { Mechanism }\end{array}$} & & Continuity & Hybrid & Hybrid \\
\hline & $\begin{array}{l}\text { Market } \\
\text { Type }\end{array}$ & $\begin{array}{l}\text { Market } \\
\text { Makers }\end{array}$ & No Market Maker & Market Maker \\
\hline & & Automation & Electronic System & Electronic System \\
\hline & \multirow{2}{*}{\multicolumn{2}{|c|}{ Trading Sessions }} & 9:30-11:30 & 10:00-12:30 \\
\hline & & & $13: 00-15: 00$ & $14: 30-16: 00$ \\
\hline & \multicolumn{2}{|c|}{ Order Forms } & Limit Orders & Limit \& Fill or Kill Orders \\
\hline & \multicolumn{2}{|c|}{ Transparency } & Semi-Transparency & Semi-Transparency \\
\hline \multirow{7}{*}{$\begin{array}{c}\text { Market } \\
\text { Regulation }\end{array}$} & \multirow{2}{*}{$\begin{array}{c}\text { Order } \\
\text { Priority }\end{array}$} & Call Auction & Price/Time & Order Type/Price/Time \\
\hline & & $\begin{array}{l}\text { Continuous } \\
\text { Trading }\end{array}$ & Price/Time & Price/Time \\
\hline & \multicolumn{2}{|c|}{ Tick Size } & CNY 0.01 & Variable \\
\hline & \multicolumn{2}{|c|}{ Trading Unit } & 100 Shares & Odd Lot or 100 Shares \\
\hline & \multicolumn{2}{|c|}{ Price Thresholds } & $10 \%$ & No \\
\hline & \multicolumn{2}{|c|}{ Shorting Selling } & Forbidden & Available (Selected) \\
\hline & \multicolumn{2}{|c|}{ Off-Market Trading } & Forbidden & Allowed \\
\hline \multirow{4}{*}{$\begin{array}{c}\text { Other Related } \\
\text { Rules }\end{array}$} & Settlement & Trading & $\mathrm{T}+1$ & $\mathrm{~T}+0$ \\
\hline & System & Settlement & $\mathrm{T}+1$ & $\mathrm{~T}+2$ \\
\hline & \multicolumn{2}{|c|}{$\begin{array}{c}\text { Commission \& } \\
\text { Stamp Duty }\end{array}$} & $0.255 \%$ & $0.359 \%$ \\
\hline & \multicolumn{2}{|c|}{ Main Capital Source } & Domestic & Local and Foreign \\
\hline
\end{tabular}

Note. From Charitou \& Panayides, 2009; Comerton-Forde \& Rydge, 2006; Comerton-Forde, Rydge, \& Burridge, 2007; Gerace, Tian, \& Zheng, 2009; Xu, 2000.

Compared to the Hong Kong Exchange, in which regulations and rules related to microstructure of equity market are amended and published on a regular basis, the Shanghai Stock Exchange experienced seven significant changes of market microstructure during our entire sample period. Therefore, we assume that the market microstructures before and after each date are relatively constant because of the relatively constant trading rules in the Shanghai Stock Exchange. 
Table 3 Significant Events Related to Market Microstructure in both Equity Markets

Panel A. Significant Events in Shanghai Stock Exchange

\begin{tabular}{|c|c|}
\hline Effective Date & Content of Event \\
\hline Nov. 212001 & Amendment of Trading Rules \\
\hline Dec. 012002 & A-Share Market are Opened to QFII ${ }^{14}$ \\
\hline Jan. 312004 & $\begin{array}{l}\text { Announcement of Launch of Releasing the Retained Common Shares Owned } \\
\text { by Government and Company Owners }\end{array}$ \\
\hline Jun. 022005 & Actual Launch of Releasing the Retained Common Shares \\
\hline Jul. 012006 & Amendment of Trading Rules \\
\hline Jan. 012007 & Adoption of New Accounting Reporting Standards for Listed Companies \\
\hline Nov. 232009 & Adoption of New Electronic Trading System \\
\hline \multicolumn{2}{|c|}{ Panel B. Significant Events in Hong Kong Exchanges } \\
\hline Effective Date & Content of Event \\
\hline Oct. 232000 & Implementation of AMS/3 Trading Devices ${ }^{15}$ \\
\hline Jan. 272005 & Selection Criteria of Securities for Short Selling ${ }^{16}$ \\
\hline Jun. 092005 & Reduction of Tick Size and Requirement for Market Makers \\
\hline Jul. 042005 & Reduction of Tick Size and Refinement of Quotation Rule \\
\hline Jul. 242006 & Reduction of Tick Size \\
\hline Oct. 192006 & Loosening the Selection Criteria For Short Selling \\
\hline May 262008 & Introduction of Closing Auction Session \\
\hline Mar. 232009 & Suspension of Closing Auction Session \\
\hline Jun. 282010 & Requires of Market Makers, Short Selling and Quotation \\
\hline
\end{tabular}

Note. From the China Securities Regulatory Commission, the Shanghai Stock Exchange, and the Hong Kong Exchange and Clearing $\operatorname{Ltd}^{17}$.

\subsection{Descriptive Statistics}

Due to the recent financial crisis, I divided the entire research time period into three

\footnotetext{
${ }^{14}$ Retrieved from http://www.asiaetrading.com/exchanges/china/shanghai-stock-exchange/ on 2011/9/13.

15 Prior to the adoption of AMS/3, the first and second generation of this electronic system is adopted in 1993 and 1996, respectively.

${ }^{16}$ In 1994, a pilot scheme is conducted for regulated short selling in the Hong Kong Exchange.

${ }^{17}$ The information about the update of trading rules in the Hong Kong Exchange is retrieved from http://www.hkex.com.hk/eng/rulesreg/traderules/traderuleupdate-sehk/exrule_ruleupdate.htm, in which the amendments of trading rules after Apr. 62004 are listed. The information about the trading rules from 2000 to 2003 are obtain from the booklet of A Glimpse of the Past, which is published by Hong Kong Exchange and Clearing Ltd. in May $31^{\text {st }}, 2011$.
} 
sub-periods of Pre-Financial Crisis Period, Financial Crisis Period and Post-Financial Crisis Period. A plot of the market composite indices is presented in Figure 2. The descriptive statistics for the Shanghai Composite Index and the Hong Kong Hangseng Index are reported in Table 4. The differences between the means and variance in each time period are reported in Table 5.

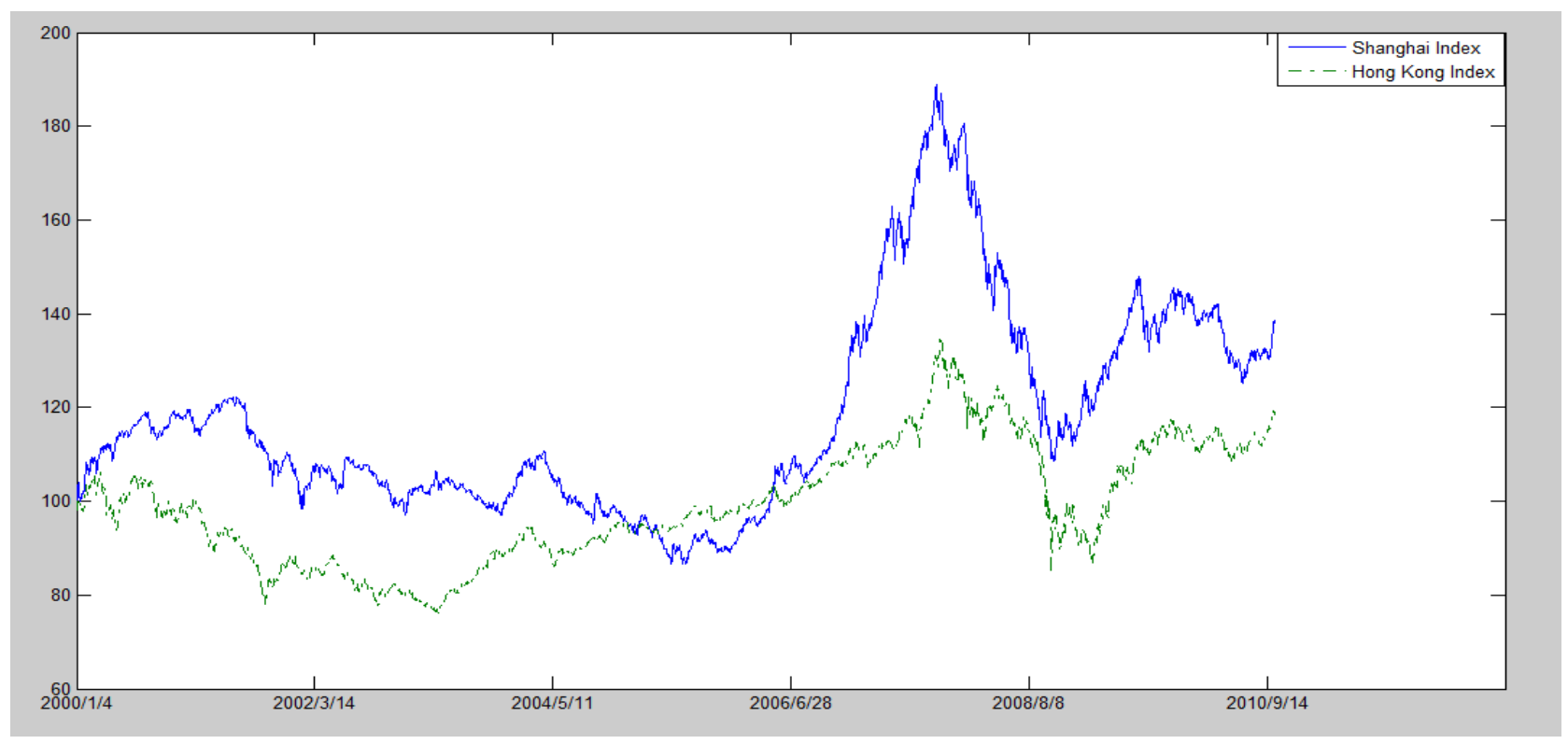

Figure 2. Market Indices in the Shanghai Exchange and the Hong Kong Exchange

Note. The solid line indicates the Market Index in the Shanghai Exchange, whereas the dash line refers to that in the Hong Kong Exchange. For the purpose of better illustration, this figure uses the market index value in each exchange at initiation as the basis value (100) to re-calculate the market index values over the study period. 


Mean S.D. Skewness Ex. Kurtosis LB(10)

Panel A. Entire Period (1/4/2000-10/20/2010)

$\begin{array}{cccccc}\text { SSE } & 0.013 & 0.762 & -0.047 & 3.753^{* * *} & 13.704 \\ \text { HKEx } & 0.006 & 0.748 & -0.076 & 7.971^{* * *} & 12.121\end{array}$

Panel B. Pre-Financial Crisis Period (1/4/2000-6/30/2007)

$\begin{array}{cccccc}\text { SSE } & 0.025 & 0.648 & 0.165 * * * & 5.494 * * * & 6.649 \\ \text { HKEx } & 0.006 & 0.574 & -0.370^{* * *} & 4.309 * * * & 11.804\end{array}$

Panel C. Financial Crisis Period (7/1/2007-6/30/2009)

$\begin{array}{cccccc}\text { SSE } & -0.023 & 1.093 & -0.016 & 1.026^{* * *} & 7.241 \\ \text { HKEx } & -0.016 & 1.243 & 0.099 & 3.394 * * * & 8.622\end{array}$

Panel D. Post-Financial Crisis Period (7/1/2009-10/20/2010)

$\begin{array}{cccccc}\text { SSE } & 0.002 & 0.737 & -0.649 * * * & 1.761 * * * & 3.505 \\ \text { HKEx } & 0.035 & 0.584 & -0.198 & 0.306 & 5.700\end{array}$

Note. There are 2517 observations for each series in the entire sample period. The number of observations for Ex-Financial Crisis Period, Financial Crisis Period Post Financial Crisis Period, Period are 1735, 473, and 309, respectively. SSE and HKEx represent the Shanghai Composite Index and the Hong Kong Hangseng Index respectively. The $\mathrm{LB}(10)$ is the Bjung-Box Q-Statistics for identifying the dependency within the time series with 10-day lags. $* * * \mathrm{p}<.01$.

For the entire sample period and all of the sub-periods, both the means and standard deviations of daily gross returns are insignificant from zero. In terms of deviation from the normal distribution, the skewness in the Shanghai Stock Exchange is significant from zero except for during the Entire Period and during the Financial Crisis Period. Additionally, the Kurtosis is generally significant for both exchanges except for the Post-Financial Crisis Period in the Hong Kong Exchange. In the case of dependency within the time series of returns in each exchange, all Bjung-Box Q-statistics at 10-day lags are insignificant. However, significance of Q-statistics at the $10 \%$ level is identified for 5-day lags in the Hong Kong Exchange for the Pre-Financial Crisis. 
Table 5 Paired Differences between Means of Daily Gross Returns

\begin{tabular}{lcccc}
\hline \multicolumn{1}{c}{ Time Period } & Difference of Means & P-Value & $\begin{array}{c}\text { F-Value for } \\
\text { Variance }\end{array}$ & P-Value \\
\hline Entire Period & 0.008 & 0.659 & 1.038 & 0.278 \\
Pre-Financial Crisis & 0.019 & 0.323 & 1.274 & 0.000 \\
Financial Crisis & -0.008 & 0.881 & 0.773 & 0.003 \\
Post-Financial Crisis & -0.033 & 0.361 & 1.809 & 0.000
\end{tabular}

Note. The difference of means is calculated as the mean of daily gross returns in Shanghai Stock Exchange less that in Hong Kong Exchange by using the Paired Sample T-test. The F-Value is calculated as the variance of daily gross returns in the Shanghai Stock Exchange divided by that in the Hong Kong Exchange, which is used to test if the risks in both exchanges are equal for each time period. The corresponding $\mathrm{p}$-value is the minimum significant level for the test.

In addition, as reported in Table 5, the differences between the means of returns are insignificant for the entire period and three sub-periods. However, the variances in both exchanges are significantly different for the periods of the Pre-Financial Crisis, the Financial Crisis, and the Post-Financial Crisis, which implies that the risks in both exchanges are different within each time period.

Tables 6 and 7 report the differences of means and variances between different pairs of time periods and associated p-values. In the case of the difference in means, no significant difference is observed for all pairs of the sub-periods in both exchanges. However, variance (or risk) is generally significantly different except for the pair in the Entire Period and the Post-Financial Crisis Period in the Shanghai Stock Exchange, and the pair in the Pre-Financial Crisis Period and the Post-Financial Crisis Period in the Hong Kong Exchange. 
Table 6 Differences of Means between Times Periods in Both Exchanges

Panel A. Difference of Means in Shanghai Stock Exchange

Entire Pre-Crisis Crisis Post-Crisis

Entire

\begin{tabular}{cccc} 
Pre-Crisis & -0.012 & & \\
& $(0.583)$ & & \\
Crisis & 0.037 & 0.048 & \\
& $(0.487)$ & $(0.357)$ & \\
Post-Crisis & 0.011 & 0.023 & -0.026 \\
& $(0.805)$ & $(0.609)$ & $(0.696)$ \\
\hline
\end{tabular}

Panel B. Difference of Means in Hong Kong Exchange

Entire Pre-Crisis Crisis Post-Crisis

Entire

\begin{tabular}{cccc} 
Pre-Crisis & -0.001 & & \\
& $(0.979)$ & & \\
Crisis & 0.021 & 0.022 & \\
& $(0.721)$ & $(0.713)$ & \\
Post-Crisis & -0.029 & -0.029 & -0.050 \\
& $(0.421)$ & $(0.423)$ & $(0.446)$ \\
\hline
\end{tabular}

Note. The value in each cell is calculated as the mean of returns for period in the title row less that for period in the title column. For example, cell in the row 3 and column 2 is the mean of returns for the Pre-Financial Crisis less that for the Financial Crisis Period. For comparing the means, we assume that the variances are neither known nor equal, and that the distributions in both exchanges are non-normal. However, since the sample size is consistently greater than 300 , the T-test can still be used. The degree of freedom for the T-test is generated from the variances for both sets of returns and the numbers of observations. 
Table 7 Differences of Variances between Time Periods in Both Exchanges

Panel A. F-Value for Ratios of Variances in Shanghai Exchange

Entire Pre-Crisis Crisis Post-Crisis

Entire

\begin{tabular}{|c|c|c|c|}
\hline Pre-Crisis & $\begin{array}{c}1.381 \\
(0.000)\end{array}$ & & \\
\hline Crisis & $\begin{array}{c}0.486 \\
(0.000)\end{array}$ & $\begin{array}{c}0.352 \\
(0.000)\end{array}$ & \\
\hline Post-Crisis & $\begin{array}{c}1.068 \\
(0.244)\end{array}$ & $\begin{array}{c}0.773 \\
(0.002)\end{array}$ & $\begin{array}{c}2.199 \\
(0.000)\end{array}$ \\
\hline
\end{tabular}

Entire

$\begin{array}{cccc}\text { Pre-Crisis } & 1.699 & & \\ & (0.000) & & \\ \text { Crisis } & 0.362 & 0.213 & \\ & (0.000) & (0.000) & \\ \text { Post-Crisis } & 1.639 & 0.965 & 4.531 \\ & (0.000) & (0.342) & (0.000)\end{array}$

Note. The value in each cell is calculated as the variance of returns for the period listed in the title row divided by that for the period listed in the title column. For example, the cell in the row 3 and column 2 is calculated as the variance of returns for the Pre-Financial Crisis Period divided by that for the Financial Crisis Period. Each of the degree of freedom for F-test is calculated as the corresponding number of observations less one. 


\section{Research Models}

In this section, underlying logic for further examination is explained and the testable regression models are presented.

First, the market microstructure influences the internal market efficiency, but the type of change in the market microstructure determines the specific effect. Second, given the internal market efficiency in each market, the high degree of the market co-movement is associated with weak cross-market efficiency of the two markets. On the other hand, given the market co-movement, as the degree of the internal market efficiency of either market increases, the cross-market efficiency between the two markets improves.

To test the relationship among the market co-movement, the internal market efficiency and the cross-market efficiency, the following linear regression model is estimated:

$$
\text { MutualInfo }_{i}=\alpha+\beta_{1} \text { Entropy }_{S H, i}+\beta_{2} \text { Entropy }_{H K, i}+\beta_{3}\left|R_{H O}\right|+\varepsilon_{i}
$$

MutualIn $o_{i}{ }^{18}$ refers to the mutual information between the two markets at time point $i$ and stands for the cross-market efficiency. Entropy $y_{S H, i}$ and Entropy $y_{H K, i}{ }^{19}$ stand for the values of entropy in the Shanghai Exchange and the Hong Kong Exchange at time point $i$ and for the internal market efficiency in each market, respectively. $R H O_{i}$ relates to the Pearson's Correlation Coefficients based on the same underlying observations with the computation of the entropies, and stands for the market co-movement. The operator $|*|$ indicates the absolute value of *. Furthermore, the higher the value of the MutualInfo ${ }_{i}$, the less efficient the cross-market efficiency is. The higher the value of the Entropy $_{S H, i}$ and Entropy ${ }_{H K, i}$, the more efficient the internal market efficiency of each exchange. Furthermore, the higher the absolute value of the Pearson's Correlation Coefficient, the higher degree

\footnotetext{
${ }^{18}$ Mutualinfo $(X ; Y)=\sum \sum f_{X, Y}(x, y) \log \frac{f_{X, Y}(x, y)}{f_{X}(x) f_{Y}(y)}$, the value is in the range of 0 and 1 .

$19 \operatorname{Entropy}(X)=-\sum f_{X}(x) \log \left(f_{X}(x)\right) / \log (n)$, the value is in the range of 0 and 1 .
} 
of the co-movement between the two markets.

Hence, I predict that the signs of the $\beta_{1}$ and $\beta_{2}$ are negative, if each market becomes more efficient, then the return in each exchange moves more randomly and it is more difficult to predict the following returns. Additionally, the sign of $\beta_{3}$ is expected to be positive. Given that the two markets are inefficient, the stronger co-movement the two markets experience, the higher predictability of the historical information and the lower the degree of the cross-market efficiency.

Furthermore, as the difference on market microstructure between the two markets decreases, the investors' behavior in each market become more similar. As a result, the change of the internal market efficiency would have an effect on the market co-movement. Thus, I expect significant effect of interactions of the three independent variables. Hence, this study controls for the interaction effects using equation (2):

$$
\begin{aligned}
\text { Mutualinfo }_{i} & =\alpha+\beta_{1} \text { Entropy }_{S H, i}+\beta_{2} \text { Entropy }_{H K, i}+\beta_{3} \mid \text { RHO }_{i} \mid+\beta_{4} \text { Entropy }_{S H, i} \\
& * \text { Entropy }_{H K, i}+\beta_{5} \text { Entropy }_{S H, i} *\left|R H O_{i}\right|+\beta_{6} \text { Entropy }_{H K, i} *\left|R H O_{i}\right| \\
& +\varepsilon_{i}
\end{aligned}
$$

Entropy $_{S H, i} *$ Entropy $_{H K, i}$, Entropy $_{S H, i} *\left|R H O_{i}\right|$, and Entropy $_{H K, i} *\left|R H O_{i}\right|$ relate to the interaction effects among the three independent variables. 


\section{Regression Results}

In this section, the empirical results of market co-movement are reported. The impact of each event on co-movement is examined by comparing the difference of the internal market efficiency around the effective dates of changes of equity market microstructure.

\subsection{Market Co-movement}

The co-movement pattern between daily gross returns in the Shanghai Stock Exchange and the Hong Kong Exchange are generated based on the mother wavelet of Morlet ${ }^{20}$ and the closing values of market composite indices. By using the squared wavelet coherence, I can examine the co-movement pattern from both time and frequency domains in Figure 3 rather than solely from the frequency domain through traditional correlation techniques.

From the analysis of the squared wavelet coherence, the co-movement pattern can be investigated from different frequency (or scale) levels. First, at high frequency level (such as on daily or weekly basis), no persistently strong correlation is observed except for the recent financial crisis period. However, in the case of intermediate frequency level (such as on monthly or quarterly basis), relatively strong correlations are observed. In addition, stronger co-movement patterns are identified for the period before the first half of 2006 rather than later periods. The above findings are consistent with the general belief that high frequency data contain too much noise and lower frequency data (such as monthly) is stable when analyzing financial time series. Finally, at low frequency level (such as on annual or bi-annual basis), persistent and strong co-movement between returns of Shanghai Stock Exchange Index and the Hong Kong Exchange Index are found. This co-movement implies that the two markets are co-integrated together in the long run, and therefore limit the potential

\footnotetext{
${ }^{20}$ Although it is suggested by many researchers that the mother wavelet of Daubechies with a scale of 4-8 is appropriate for financial time series analysis, in this study, the mother wavelet of Morlet is manipulated since smoothing operators are specially designed for calculating wavelet coherence. The program for calculating squared wavelet coherence is based on the work of Grinsted, Moore and Jevrejeva (2004), which was retrieved from http://www.pol.ac.uk/home/research/waveletcoherence/
} 
benefit for diversification strategies in these two markets. The above observations are consistent with the result of Christoffersen et al. (2011).

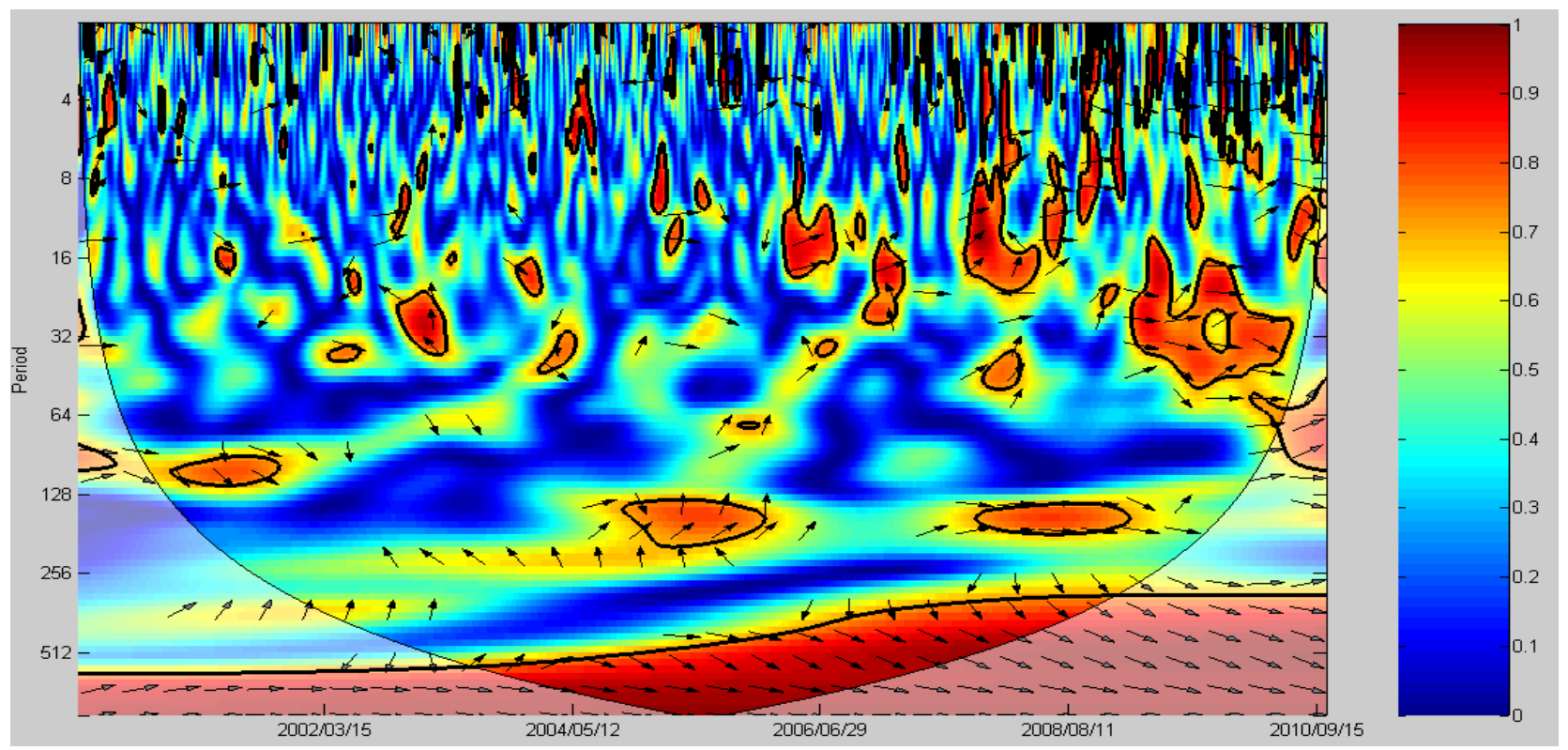

Figure 3. Squared Wavelet Coherence for Market Co-movement

Note. The value of squared wavelet coherence is in the range of 0 and 1. A leftward arrow indicates a negative relationship between the two time series, and a rightward arrow implies a positive correlation. The higher the value of squared wavelet coherence, the stronger correlation between the two time series. The scale (or frequency) of analyzing is indicated by the vertical axis, while the time interval is indicated by the horizontal axis. Moreover, the bold line suggests the significance level at 5\% level which is determined by Monte Carlo simulation of 10,000 sets of two white noise time series with the same length as the series in this study, as suggested by Rua and Nunes (2009).

\subsection{Internal Market Efficiency}

In this study, internal market efficiencies in both the Shanghai Stock Exchange and the Hong Kong Stock Exchange are examined by using daily price normalized entropy. In this section, the window length of 90 trading days is chosen to be neither too long nor too short to capture the essential internal predictability in the market. The normalized entropy in both markets for the entire study periods is reported in Figure 4.

The solid line outlines the entropy in the Shanghai Exchange with the given window length of 90 trading days. The dot line indicates the entropy in the Hong Kong Exchange with the same 
window. This calculation is based on the work of Peng (2007).

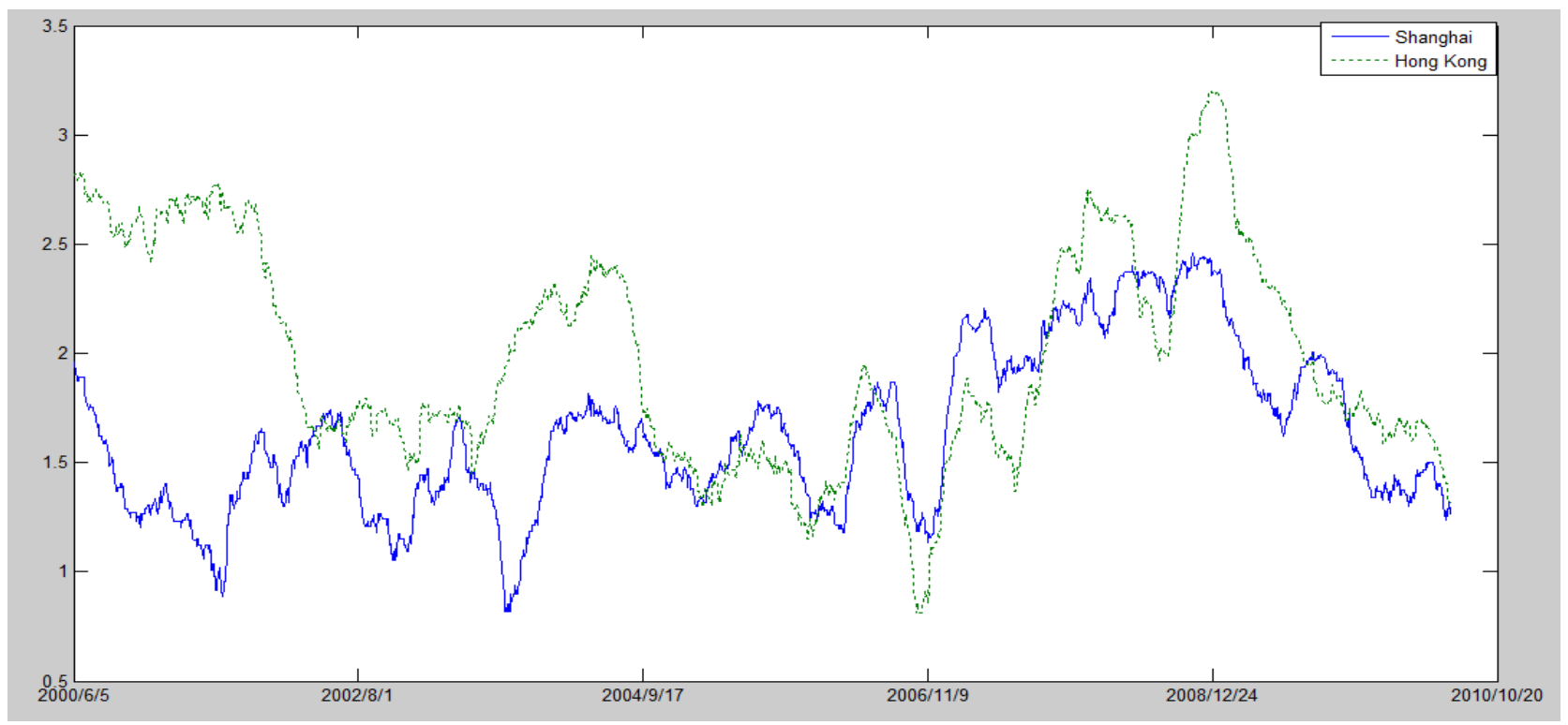

Figure 4. Normalized Entropy for the Shanghai Exchange and Hong Kong Exchange

Note. The value of normalized entropy is between 0 and 1 . A high value of normalized entropy indicates a more efficient market, and vice versa. The calculation of entropy is based on successive 90 trading days, and thus there are 2428 observations in each entropy series. The logarithm calculation is on the base of 2 .

Figure 4 shows that the degrees of the internal market efficiency of the two markets are time-varying. An interesting observation is that the Hong Kong Exchange is not always more efficient than the Shanghai Exchange, which is contrary to our general belief that the developed market (the Hong Kong Stock Exchange) is always more efficient than the emerging market (the Shanghai Stock Exchange). There are two possible explanations for this observation. First, the measurement of the internal market efficiency is mainly from the perspective of predictability of return series. Second, the observation is based on the unique setting that both markets are under the regulation of Chinese government. Thus, the results reached may be different with those in American markets or European markets.

\subsection{Cross-Market Efficiency}


In this section the result of cross-market efficiency between the Shanghai Exchange and Hong Kong Exchange is reported in Figure 5 based on the calculation of mutual information. ${ }^{21}$

Based on Figure 5, the Shanghai and Hong Kong Exchanges are generally dependent on each other during the entire study period. The degree of dependency was relatively high during the recent financial crisis and returned to a relatively low level during post-crisis period, but stayed at a higher level compared to the degree of dependency in Pre-Crisis period.

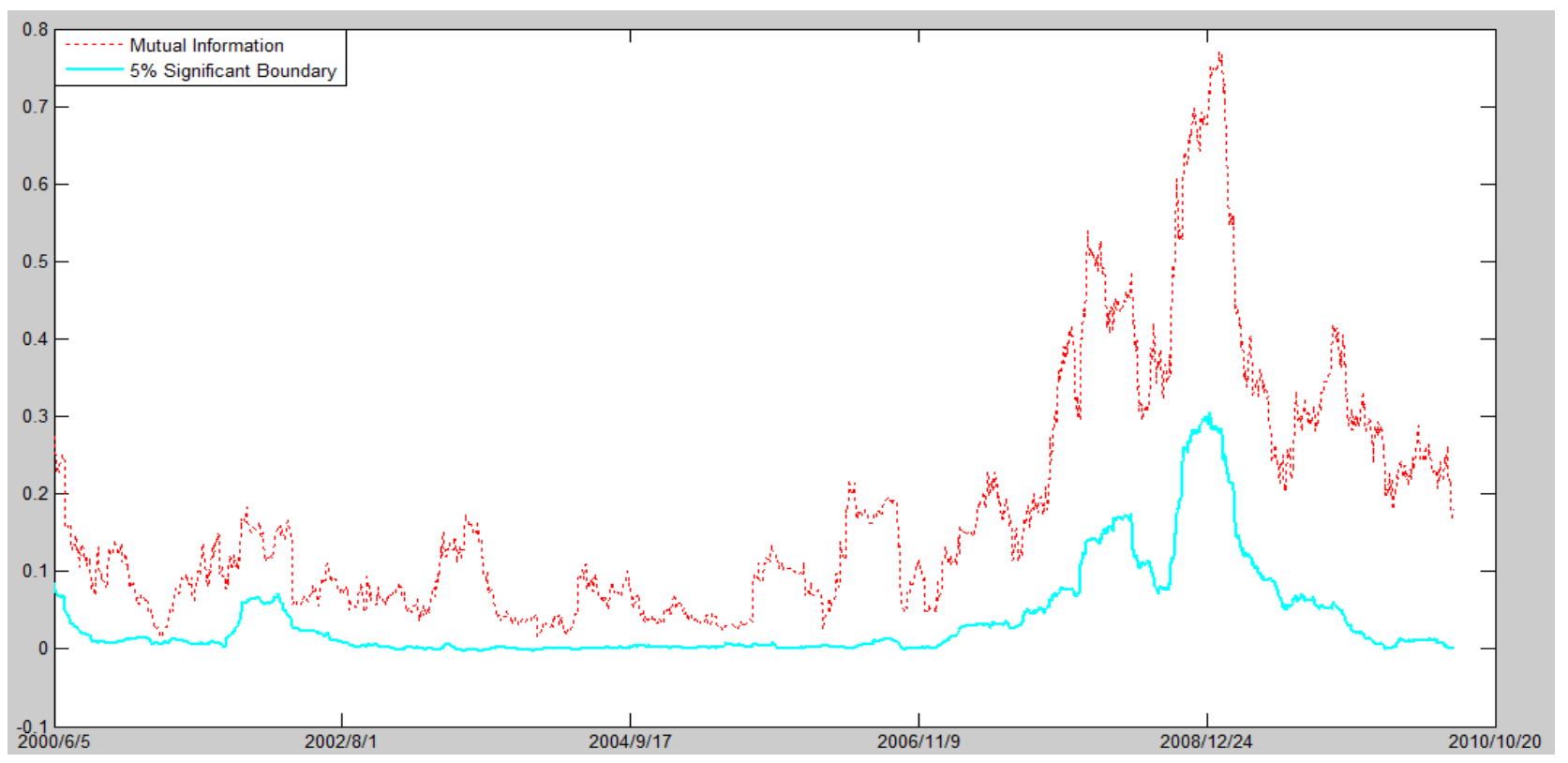

Figure 5. Normalized Mutual Information between the Two Markets

Note. The dot line indicates the normalized mutual information, and the bold line suggests the significance level at $5 \%$ level which is determined by Monte Carlo simulation of 10,000 pairs of two white noise time series with the same means and standard deviations as the underlying return series. The value of mutual information is between 0 and 1 , and the higher the value, the greater the dependency between the two sets of time series. If the value of mutual information is greater than the significant value with the same date, the mutual information is significant different from zero, which means the two sets of time series are dependent.

\subsection{Regression Analysis}

In this section, I examine the relationship among cross-market efficiency, internal market efficiencies, and market co-movement for the market in normal condition (from January 1, 2000 to

\footnotetext{
${ }^{21}$ The matlab program of calculating the entropy and the mutual information are based on the work of Peng (2007).
} 
June 30, 2006). To account for the inaccuracy problem brought on by the heteroskedasticity ${ }^{22}$, White's robust standard errors are used, and the corresponding results are reported in Table 8.

Table 8 Relationship among Market Co-Movement, Market Efficiency and Cross-Market Efficiency during Normal Period

\begin{tabular}{|c|c|c|c|c|}
\hline & 1 & 2 & 3 & 4 \\
\hline Intercept & $-0.049 * * *$ & $0.064 * * *$ & $-0.051 * * *$ & $0.130 * * *$ \\
\hline Entropy $_{S H, i}$ & $0.309 * * *$ & - & $0.222 * * *$ & $-0.618 * * *$ \\
\hline Entropy $_{H K, i}$ & $0.390 * * *$ & - & $0.392 * * *$ & -0.209 \\
\hline$\left|R H O_{i}\right|$ & - & $0.156^{* * *}$ & $0.141 * * *$ & $-0.413 * *$ \\
\hline Entropy $_{S H, i} *\left|R H O_{i}\right|$ & - & - & - & $2.490 * * *$ \\
\hline Entropy $_{H K, i} *\left|R H O_{i}\right|$ & - & - & - & 0.299 \\
\hline Entropy $_{S H, i} *$ Entropy $_{H K, i}$ & - & - & - & $2.607 * *$ \\
\hline Adjusted R-squared & 0.285 & 0.083 & 0.346 & 0.397 \\
\hline
\end{tabular}

Note. There are 1412 observations for each variable. The dependent variable is the MutualInfo ${ }_{i}$, which stands for the cross-market efficiency. The Entropy $\mathrm{SH}_{\mathrm{i}, \mathrm{i}}$, and Entropy $\mathrm{HK}_{\mathrm{H}, \mathrm{i}}$ stand for the internal market efficiency in the Shanghai Exchange and the Hong Kong Exchange, respectively. $\left|\mathrm{RHO}_{\mathrm{i}}\right|$ represents the market co-movement. To correct for the problems of heteroskedasticity, White's robust standard error method is used.

$* * \mathrm{p}<.05 . * * * \mathrm{p}<.01$

The first three columns separately report the effects of the internal market efficiency, the market co-movement and their combined influence on the cross-market efficiency. All coefficients are significant at the $1 \%$ level. After controlling for the interaction effects between internal market efficiency and market co-movement, the coefficients of $\beta_{1}$ and $\beta_{3}$ are negatively significant at the $1 \%$ level, whereas the coefficient of $\beta_{2}$ is negative but insignificant even at the $10 \%$ level. The sign of $\beta_{1}$ and $\beta_{2}$ are consistent with my hypothesis, which suggests that the more efficient the internal market efficiency in each market is, the higher the degree of the cross-market efficiency. However,

\footnotetext{
${ }^{22}$ I also examine the existence of serial correlation within time series. Based on the regression result, no serial correlation is detected.
} 
$\beta_{3}$ is opposite to my prediction, which suggests that strong co-movement between the two markets is associated with deterioration of the cross-market efficiency. This finding is consistent with the argument that market co-movement does not imply cross-market inefficiency. 


\section{Explanations}

In this section, I study two interesting time periods within the study period: Retained common shares releasing period (hereafter releasing period) and the financial crisis period. I examine the relationship among cross-wavelet coherence, internal market efficiency, and cross-market efficiency.

\subsection{Period of Releasing Retained Common Shares in the Shanghai Exchange}

In this sub-section, I explore the relationship among the market co-movement, internal market efficiency and cross-market efficiency on one of the biggest events in the Chinese stock market history - the releasing of the retained common shares owned by government and company owners at the beginning of 2004. The release was announced by the Chinese regulators on January 31, 2004, and launched on June 2, 2005, as indicated by the releasing practice of Sany Group (SH. 600031). Thus, I choose the time period from January 1, 2003 to June 30, 2006 as the study period. The market co-movement, internal market efficiency, and cross-market efficiency are reported in the Figures 6 and 7. 


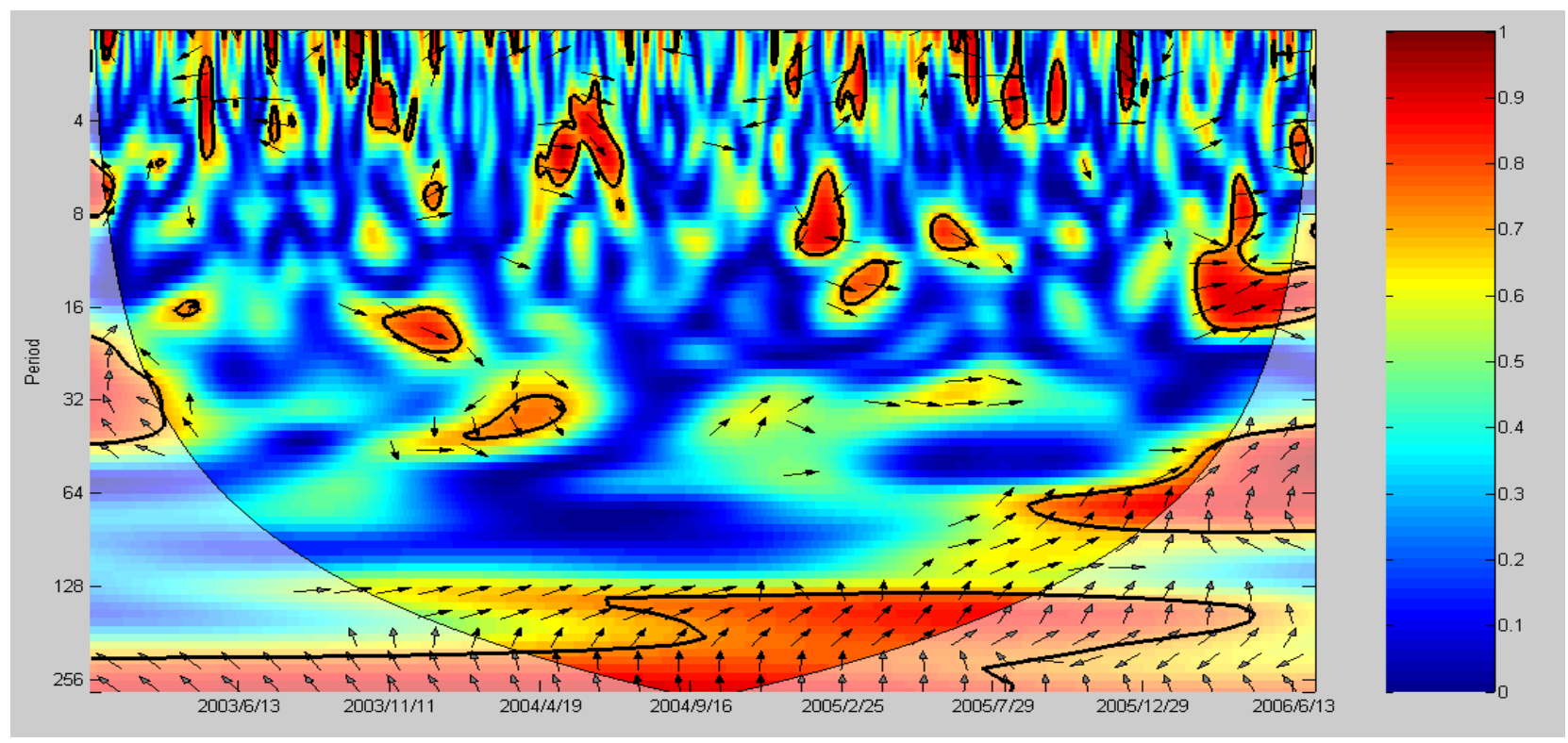

Figure 6. Wavelet Coherence between the two Markets during the Leasing Period

Note. The value of squared wavelet coherence is in the range of 0 and 1. A leftward arrow indicates a negative relationship between the two time series, and a rightward arrow implies a positive correlation. The higher the value of squared wavelet coherence, the stronger correlation between the two time series. The scale (or frequency) of analyzing is indicated by the vertical axis, while the time interval is indicated by the horizontal axis. Moreover, the bold line suggests the significance level at 5\% level, which is determined by Monte Carlo simulation of 10,000 sets of two white noise time series with the same length as the series.

Regarding the market co-movement, strong and significant co-movement is observed at low frequency level (e.g., annually). At the high (e.g., weekly) and intermediate (e.g., monthly or quarterly) frequency level, weaker market co-movement is observed, compared to the financial crisis period. 


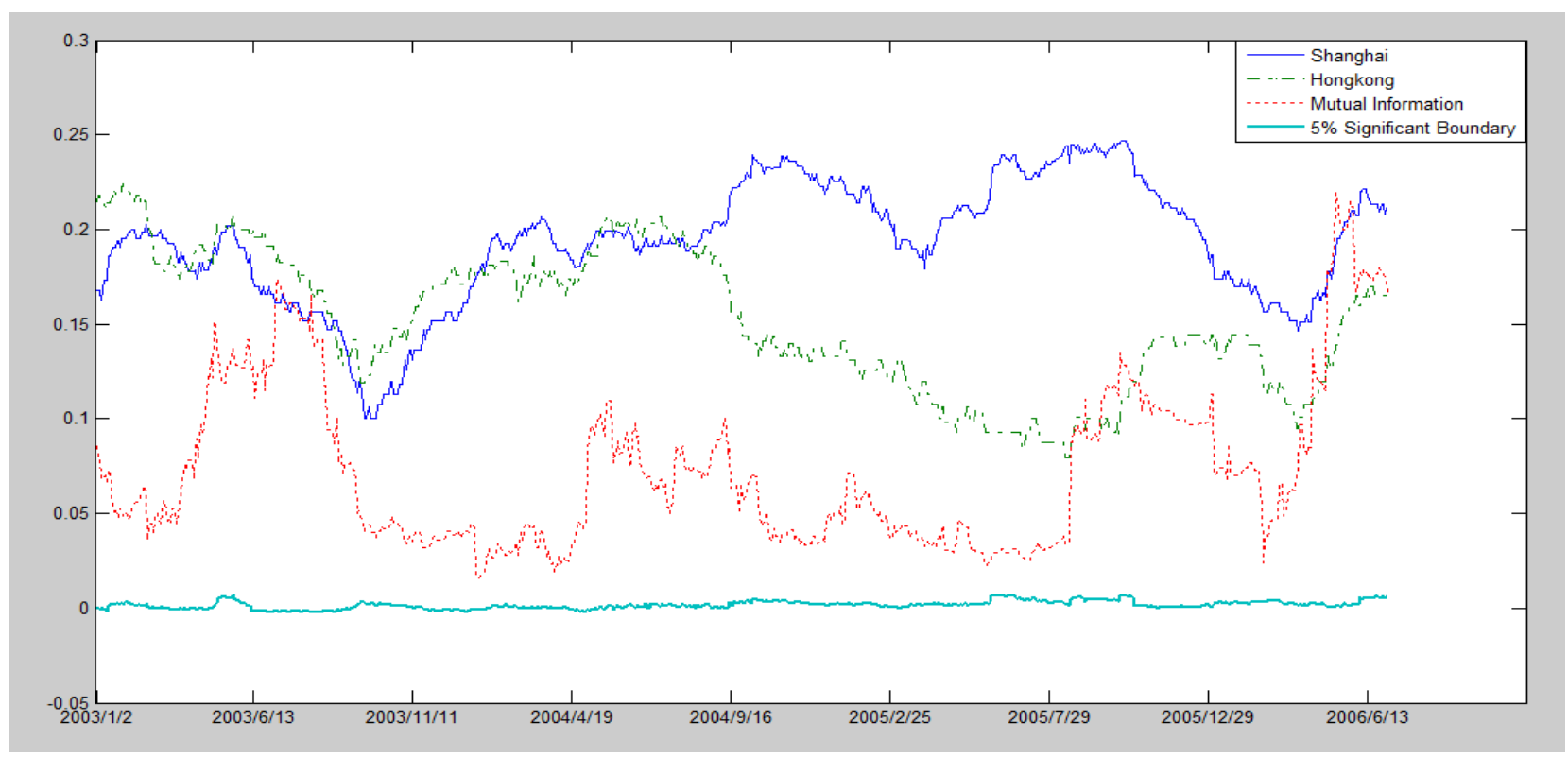

Figure 7. Normalized Entropy and Mutual Information in both Markets during the Releasing Period Note. The solid line indicates the internal market efficiency of the Shanghai Exchange during the financial crisis, the dash line suggests the internal market efficiency of the Hong Kong Exchange, and the dot line refers to the cross-market efficiency between these two markets. The bold line suggests the 5\% significant level of mutual information based on the Monte Carlo simulations of 10,000 pairs of white noises with the same means and standard deviations as the underlying return series. All the calculations are based on the previous 90 days return series.

Table 9 Effect of the Change of the Market Microstructure during the Releasing Period

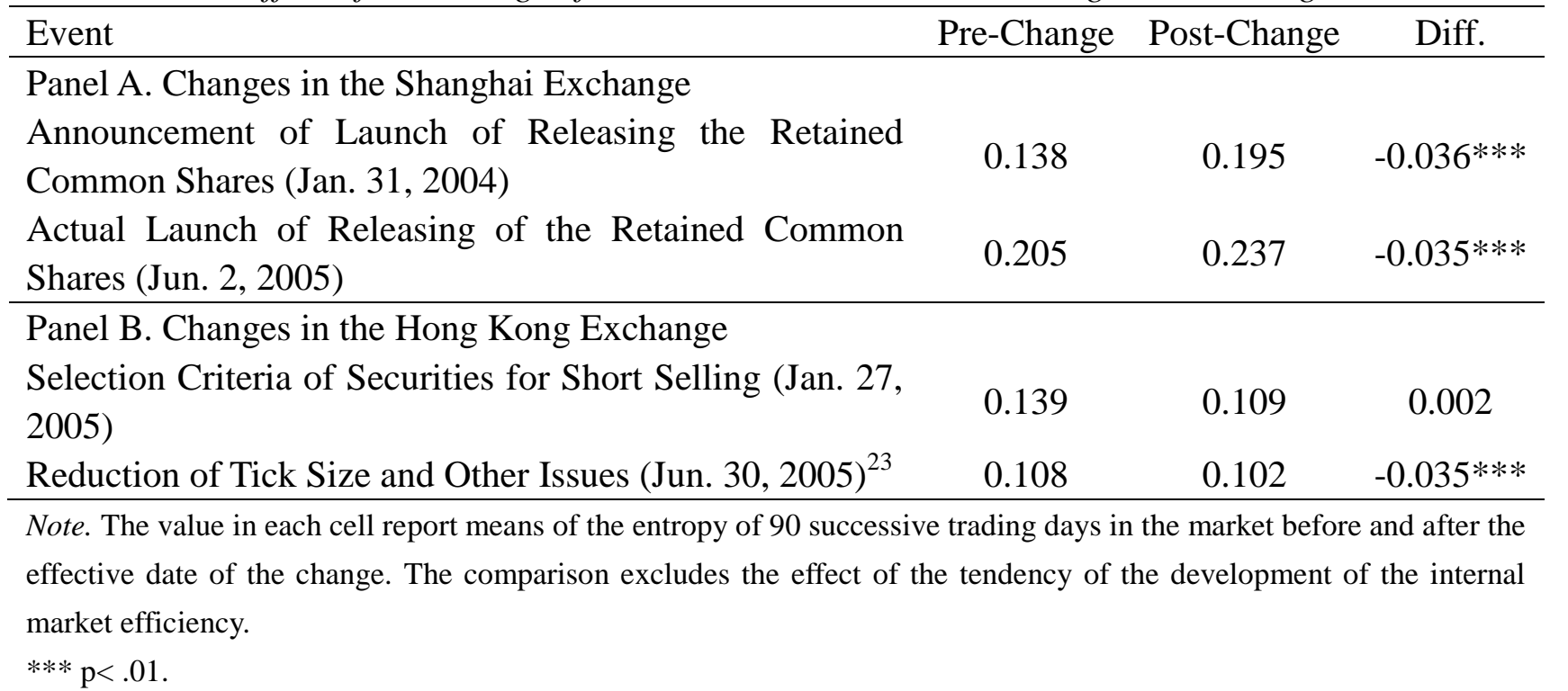

Table 9 reports the differences of the internal market efficiency before and after the change of

\footnotetext{
${ }^{23}$ Two events happened closely, Reduction of Tick Size and Requirement for Market Makers on Jun. 9, 2005 and Reduction of Tick Size and Refinement of Quotation Rule on Jul. 4, 2005, respectively.
} 
the market microstructure in each exchange after controlling for the time trend. All of the differences before and after changes, except for the event of modifying the selection criteria for short selling in the Hong Kong Exchange, are significant at the $1 \%$ level.

In the case of cross-market efficiency, although the two markets are significantly dependent, there are three increases during the study period before the degree of the cross-market efficiency returns back to its original level.

The relationship among the cross-market efficiency, the internal market efficiency and the market co-movement during the releasing period is reported in Table 10.

Table 10 Relationship among Market Co-Movement, Market Efficiency and Cross-Market Efficiency during the Releasing Period

\begin{tabular}{|c|c|c|c|c|}
\hline & 1 & 2 & 3 & 4 \\
\hline Intercept & 0.018 & $0.064 * * *$ & 0.011 & $0.208 *$ \\
\hline Entropy $_{S H, i}$ & 0.072 & - & 0.045 & $-1.522 * *$ \\
\hline Entropy $y_{H K, i}$ & $0.273 * * *$ & - & $0.286 * * *$ & -0.664 \\
\hline$\left|R H O_{i}\right|$ & - & $0.059^{*}$ & $0.069 * *$ & 0.109 \\
\hline Entropy $_{S H, i} *\left|R H O_{i}\right|$ & - & - & - & $3.321 * * *$ \\
\hline Entropy $_{H K, i} *\left|R H O_{i}\right|$ & - & - & - & $-4.567 * * *$ \\
\hline Entropy $_{S H, i} *$ Entropy $_{H K, i}$ & - & - & - & $8.586^{*}$ \\
\hline Adjusted R-squared & 0.050 & 0.015 & 0.071 & 0.204 \\
\hline
\end{tabular}

Note. There are 813 observations for each variable. The dependent variable is the MutualInfo ${ }_{i}$, which stands for the cross-market efficiency. The Entropy $y_{S H, i}$, and Entropy ${ }_{H K, i}$ stand for the internal market efficiency in the Shanghai Exchange and the Hong Kong Exchange, respectively. $\left|\mathrm{RHO}_{\mathrm{i}}\right|$ represents the market co-movement. White's robust standard errors method is used to account for the heteroskedasticity.

$* \mathrm{p}<.10 . * * \mathrm{p}<.05 . * * * \mathrm{p}<.01$.

The first three columns separately report the effects of the internal market efficiency in each market, the market co-movement and their combination against the cross-market efficiency. After 
controlling for the interaction effects, the coefficient of the internal market efficiency of the Shanghai Exchange is negative and significant at the 5\% level, which implies that, during the releasing period, the internal market efficiency of the Shanghai Exchange is positively related to the cross-market efficiency. On the other hand, the coefficient of the internal market efficiency of the Hong Kong Exchange is negative but insignificant. This finding suggests that the cross-market efficiency is mainly affected by the internal market efficiency of the emerging market (the Shanghai Stock Exchange) rather than the internal market efficiency of the developed market (the Hong Kong Stock Exchange). Regarding the effect of the market co-movement, the coefficient is positive but insignificant, which implies that the market co-movement has no effect on the cross-market efficiency. Additionally, the regression results of the interaction terms are significant at the $1 \%$ level, except for the interaction term between the internal market efficiency of the Shanghai Exchange and that of the Hong Kong Exchange.

\subsection{Financial Crisis Period}

In the financial crisis period, the market is dominated by downward tendency and greater volatility. In this section, I examined the performances of market co-movement, internal market efficiencies, and cross-market efficiency in the Figures 8 and 9 for the recent financial crisis (from July 3, 2007 to March 31, 2009). Additionally, I include the time period from July 3, 2006 to June 30, 2007 into the study to enrich our knowledge about the two markets before and during the financial crisis. Since the financial crisis may have non-negligible effects on the significant events in the market, this sub-section focuses on the influence of the financial crisis on the two markets. 


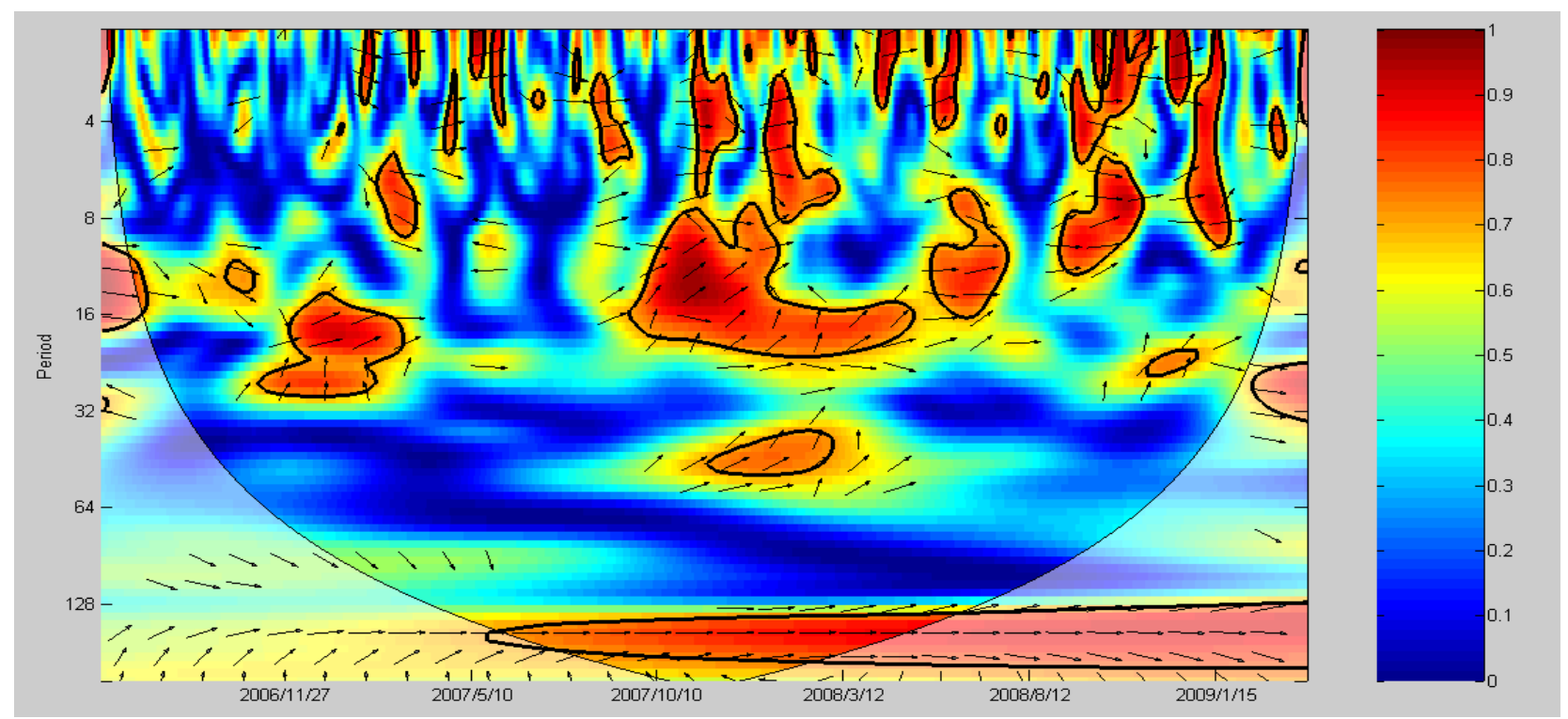

Figure 8. Wavelet Coherence between the two Markets during the Financial Crisis Period

Note. The value of squared wavelet coherence is in the range of 0 and 1. A leftward arrow indicates a negative relationship between the two time series, and a rightward arrow implies a positive correlation. The higher the value of squared wavelet coherence, the stronger correlation between the two time series. The scale (or frequency) of analyzing is indicated by the vertical axis, while the time interval is indicated by the horizontal axis. Moreover, the bold line suggests the significance level at $5 \%$ level, which is determined by Monte Carlo simulation of 10,000 sets of two white noise time series with the same length as the series.

During the financial crisis period, there are multiple significant events in both the Shanghai and Hong Kong Exchanges. ${ }^{24}$ In the case of market co-movement, there is a significant co-movement between the two markets at the end of 2006 at the intermediate frequency. However, during the financial crisis, significant co-movement can be observed at all frequencies.

\footnotetext{
${ }^{24}$ There are two significant events in the Shanghai Exchange; these are the Amendment of Trading Rules in Jul. 1, 2006 and the Adoption of New Accounting Reporting Standards for Listed Companies in Jan. 1, 2007. And there are three significant events in the Hong Kong Exchange, Loosening the Selection Criteria For Short Selling in Oct. 19, 2006, Introduction of Closing Auction Session in May 26, 2008, and Suspension of Closing Auction Session in Mar. 23, 2009, respectively.
} 


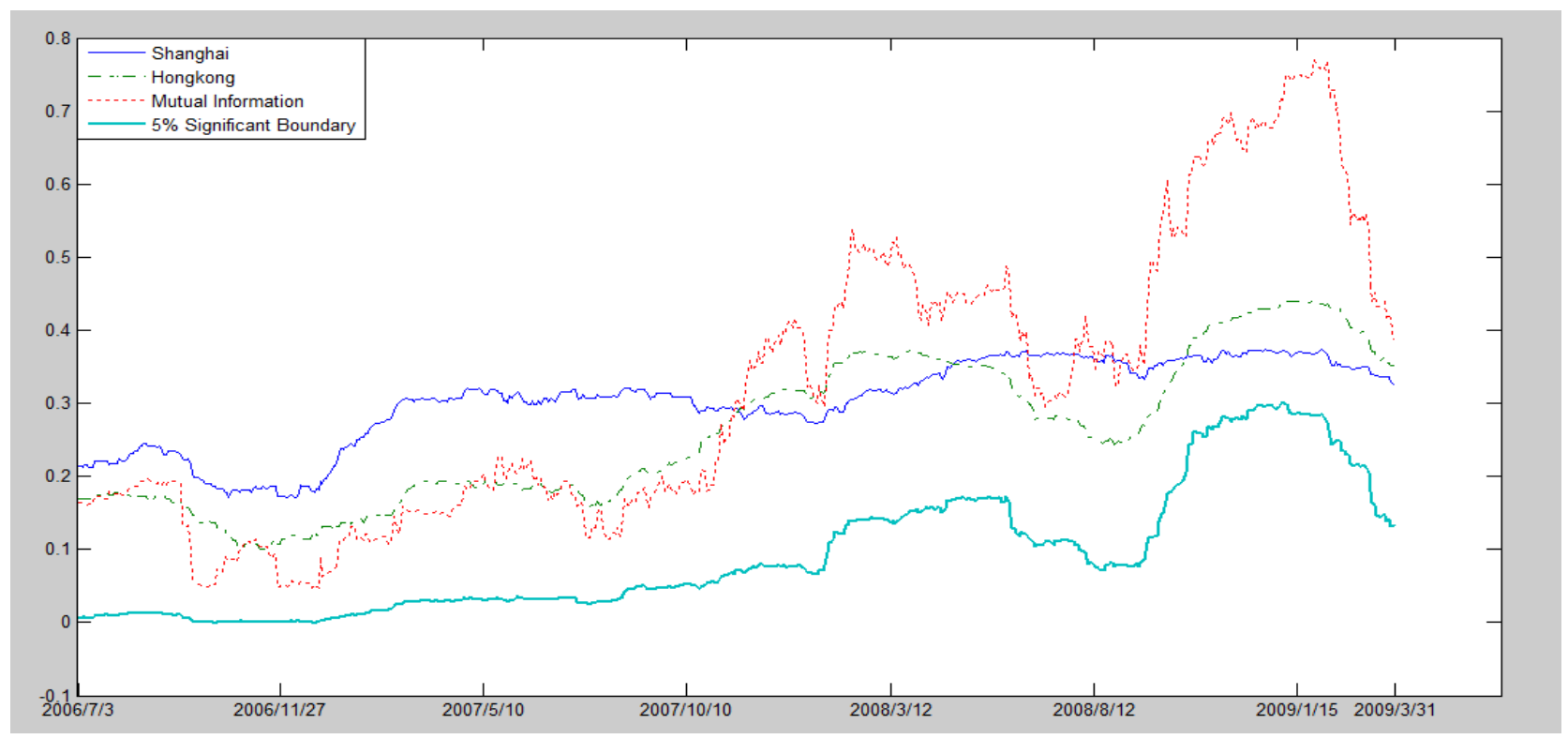

Figure 9. Normalized Entropy and Mutual Information in both Markets during the Financial Crisis Note. The solid line indicates the internal market efficiency of the Shanghai Exchange during the financial crisis, the dash line suggests the internal market efficiency of the Hong Kong Exchange, and the dot line refers to the cross-market efficiency between these two markets. The bold line suggests the 5\% significant level of mutual information based on the Monte Carlo simulations of 10,000 pairs of white noises with the same means and standard deviations as the underlying return series. All the calculations are based on the previous 90 days return series.

I compare the internal market efficiencies before and after the change in order to examine the effects of the change of the market microstructure. The comparison is based on the normalized entropy values of 90 successive trading days and excludes the effect of tendency. The results are reported in Table 9. 
Table 11 Effect of the Change of the Market Microstructure during the Financial Crisis Period

\begin{tabular}{lccc}
\hline Event & Pre-Change & Post-Change & Diff. \\
\hline $\begin{array}{l}\text { Panel A. Changes in the Shanghai Exchange } \\
\text { Amendment of the Trading Rules (Jul. 1, 2006) }\end{array}$ & 0.179 & 0.211 & $0.013^{* * *}$ \\
$\begin{array}{l}\text { Adoption of the New Accounting Reporting Standards } \\
\text { (Jan. 1, 2007) }\end{array}$ & 0.197 & 0.287 & $-0.156^{* * *}$ \\
\hline $\begin{array}{l}\text { Panel B. Changes in the Hong Kong Exchange } \\
\text { Loosening the Selection Criteria For Short Selling (Oct. }\end{array}$ & 0.166 & 0.124 & $0.007^{* * *}$ \\
$\begin{array}{l}\text { 19, 2006) } \\
\text { Introduction of Closing Auction Session (May 26, 2008) }\end{array}$ & 0.354 & 0.285 & $0.097^{* * *}$ \\
Suspension of Closing Auction Session (Mar. 23, 2009) & 0.418 & 0.330 & $0.073^{* * *}$ \\
\hline
\end{tabular}

Note. The value in each cell reports means of the entropy of 90 successive trading days in the market before and after the effective date of the change. The diff. stands for the difference between the means of entropies, which is calculated as the mean of entropy before the change less that after the change. The comparison excludes the effect of the tendency of the development of the internal market efficiency.

$* * * \mathrm{p}<.01$

According to the Table 11, the changes of the microstructure have significant effect on the internal market efficiency. After the amendment of the trading rules on Jul. 1, 2006, the Shanghai Exchange was significantly less efficient. However, there is a significant improvement of the internal market efficiency after adopting the new accounting reporting standards. On the other hand, in the Hong Kong Exchange, all three events have opposite effects against the prediction that the change of the market microstructure can improve the internal market efficiency. This observation may be due to the influence of the financial crisis, during which the internal market efficiency experienced significant deterioration.

In terms of the cross-market efficiency, the dependency between the two markets is significant over the whole time period, and stays at a relatively low level before the financial crisis. However, the market dependency experiences greater fluctuation during the financial crisis. An interesting observation is that the values of the mutual information are relatively high from the second half of 2008 to March of 2009, which suggests great deterioration of the cross-market 
efficiency during this period.

The results of testing the regression models and the relationships among the market co-movement, the internal market efficiency and the cross-market efficiency are reported in Table 12.

Table 12 Relationship among Market Co-Movement, Market Efficiency and Cross-Market Efficiency during the Financial Crisis Period

\begin{tabular}{|c|c|c|c|c|}
\hline & 1 & 2 & 3 & 4 \\
\hline Intercept & $-0.188 * * *$ & $-0.132 * * *$ & $-0.177 * * *$ & $0.300 * * *$ \\
\hline Entropy $_{S H, i}$ & 0.083 & - & -0.011 & $-0.703 * * *$ \\
\hline Entropy $_{H K, i}$ & $1.850 * * *$ & - & $1.718 * * *$ & $0.608^{*}$ \\
\hline$\left|R H O_{i}\right|$ & - & $1.114 * * *$ & $0.129 *$ & $-1.792 * * *$ \\
\hline Entropy $_{S H, i} *\left|R H O_{i}\right|$ & - & - & - & $4.990 * * *$ \\
\hline Entropy $_{H K, i} *\left|R H O_{i}\right|$ & - & - & - & $2.441 * * *$ \\
\hline Entropy $_{S H, i} *$ Entropy $_{H K, i}$ & - & - & - & -1.646 \\
\hline Adjusted R-squared & 0.926 & 0.752 & 0.928 & 0.980 \\
\hline
\end{tabular}

Note. There are 648 observations for each variable. The dependent variable is the MutualInfo $\mathrm{o}_{\mathrm{i}}$, which stands for the cross-market efficiency. The Entropy ${ }_{S H, i}$, and Entropy $_{H K, i}$ stand for the internal market efficiency in the Shanghai Exchange and the Hong Kong Exchange, respectively. $\left|\mathrm{RHO}_{\mathrm{i}}\right|$ represents the market co-movement. To account for the heteroskedasticity, the method of robust standard error is used.

$* \mathrm{p}<.10 . * * * \mathrm{p}<.01$.

The first three columns report the effects of the internal market efficiency, the market co-movement and their combined influence on the cross-market efficiency. Column (4) suggests that, after controlling for the interaction effects among internal market efficiency in each market and market co-movement between the two markets, the coefficient of the internal market efficiency of the Shanghai Exchange is negative and significant at the $1 \%$ level. This result suggests that the cross-market efficiency is improved as the Shanghai Exchange becomes more efficient. On the other hand, the coefficient of the entropy in the Hong Kong Exchange is positive but insignificant at the 5\% 
level. The coefficient regarding the effect of the market co-movement is negative and significant at the $1 \%$ level, which is inconsistent with my previous prediction, and suggests that higher market co-movement is associated with higher degree of the cross-market efficiency. Additionally, in the case of the interaction effect, two of three coefficients are positive and significant at the $1 \%$ level, whereas the interaction between the two markets' entropies is negative but insignificant, even at the $10 \%$ level.

There are two interesting observations from the above regression results. First, only the coefficient of the internal market efficiency in the Shanghai Exchange is significant at the 5\% level, which suggests that the cross-market efficiency is determined only by the internal market efficiency of the emerging market rather than that of the developed market. Second, the statistics of the market co-movement reveals that during the financial crisis period, as the market co-movement became stronger, the cross-market efficiency was improving. This observation again confirms the statement that the cross-market inefficiency does not imply the market co-movement. One possible explanation is that, during the financial crisis, there are great uncertainty and volatility of investment returns, thus the best investing strategy for uninformed investors was to follow the investment decision of other successful investors who have the required information and intelligence in the market. This strategy may increase the degree of the market co-movement, but improve the cross-market efficiency by letting the price adjust to the effective price rapidly and correctly (for a summary of studies on rational herding, see Devenow \& Welch (1996)).Alternatively, during the financial crisis, the correlation between the returns series is relatively high, compared to the market in normal condition, no matter how the two markets correlated.

Furthermore, regarding the explanatory power of the regression model, the adjusted 
R-squared of the full model is extremely high (0.980) for the financial crisis period. The adjusted $\mathrm{R}$-squared is 0.204 for the releasing period, and that is 0.397 for the normal period. The significant increase of the explanatory power of the regression during the financial crisis period maybe a result of the market when it is in extreme condition. The market is extremely volatile and the internal market efficiency in each market become more important for investors' decision. 


\section{Robustness}

In this section, several robust checks of the results are performed. First, I select window lengths of 60 days (quarterly) and 120 days (semiannually) rather than 90 trading days to calculate the entropies, mutual information and Pearson's correlation coefficient. Second, since the underlying assets for market composite indices are different for the Shanghai and the Hong Kong composite indices, I built new pairs of indices composited by 63 cross-listing companies in both markets. This manipulation makes it possible to focus on the influence of the market co-movement and the internal market efficiency on the cross-market efficiency.

No matter which window length is selected, several commonalities can be observed. First, the explanatory power for the regression is greater for the financial crisis period than for the releasing period. This observation indicates that the cross-market efficiency is mainly determined by the internal market efficiency of the Shanghai Exchange and the market co-movement during the financial crisis period. However, the hypothesized relationship is more prominent during the financial crisis period, compared to the relationship when the market is in normal condition. Second, during the financial crisis period, coefficients suggest that the improvement of the internal market efficiency in the Shanghai Exchange can improve the cross-market efficiency. On the other hand, three of four regressions reveal that the internal market efficiency of the Hong Kong Exchange has no effect on the cross-market efficiency. Third, the market co-movement is positively related to the cross-market efficiency during the financial crisis period. However, when the market is in normal condition (e.g., releasing period), the effect of the market co-movement is insignificant at the 5\% level. In addition, regarding the effects of the interactions, the coefficients of the interaction terms of the internal market efficiency in each market against the market co-movement are significant. However, the effect of the interaction term between the two markets' internal market efficiencies is 
inconclusive.

Table 13 Relationships among Market Co-movement, Internal Market Efficiency and Cross-Market Efficiency Based on 60 Trading Days

Panel A: Releasing Period

$\begin{array}{ccccc} & 1 & 2 & 3 & 4 \\ \text { Intercept } & -0.029 & 0.071^{* * *} & -0.035 & 0.081 \\ \text { Entropy }_{S H, i} & 0.219^{* *} & - & 0.182^{*} & -0.964 * \\ \text { Entropy }_{H K, i} & 0.441^{* * *} & - & 0.433^{* * *} & 0.179 \\ \left|R H O_{i}\right| & - & 0.104 * * * & 0.089 * * & 0.096 \\ \text { Entropy }_{S H, i} *\left|R_{H} O_{i}\right| & - & - & - & 3.194 * * * \\ \text { Entropy }_{H K, i} * \mid \text { RHO }_{i} \mid & - & - & - & -4.221^{* * *} \\ \text { Entropy }_{S H, i} * \text { Entropy }_{H K, i} & - & - & - & 4.897\end{array}$

Adjusted R-squared

0.122

0.032

0.145

0.286

Panel B: Financial Crisis Period

$\begin{array}{ccccc} & 1 & 2 & 3 & 4 \\ \text { Intercept } & -0.228^{* * *} & -0.117 * * * & -0.231 * * * & 0.187 * * * \\ \text { Entropy }_{S H, i} & 0.231^{* *} & - & 0.163 & -0.561 * * * \\ \text { Entropy }_{H K, i} & 1.832 * * * & - & 1.606 * * * & 0.391 \\ \left|R H O_{i}\right| & - & 1.160^{* * *} & 0.214^{* * *} & -0.993 * * * \\ \text { Entropy }_{S H, i} *\left|R H O_{i}\right| & - & - & - & 2.775^{* * *} \\ \text { Entropy }_{H K, i} *\left|R H O_{i}\right| & - & - & - & 1.487 * * * \\ \text { Entropy }_{S H, i} * \text { Entropy }_{H K, i} & - & - & - & 0.717 \\ \text { Adjusted R-squared }_{\text {A }} & 0.906 & 0.691 & 0.913 & 0.952\end{array}$

Note. There are 648 and 813 observations for each variable for panel A and B, respectively.

$* \mathrm{p}<.10 . * * \mathrm{p}<.05 . * * * \mathrm{p}<.01$. 
Table 14 Relationships among Market Co-movement, Internal Market Efficiency and Cross-Market Efficiency Based on 120 Trading Days

Panel A: Releasing Period

$\begin{array}{ccccc} & 1 & 2 & 3 & 4 \\ \text { Intercept } & 0.090 * * * & 0.058 * * * & 0.081 * * * & 0.674 * * * \\ \text { Entropy }_{S H, i} & -0.154 & - & -0.173 & -3.604 * * * \\ \text { Entropy } y_{H K, i} & 0.013 & - & 0.043 & -3.211^{* * *} \\ \left|R H O_{i}\right| & - & 0.043 & 0.058 * * & -0.593 * \\ \text { Entropy }_{S H, i} *\left|R H O_{i}\right| & - & - & - & 5.638^{* * *} \\ \text { Entropy }_{H K, i} *\left|R H O_{i}\right| & - & - & - & -2.945^{* * *} \\ \text { Entropy }_{S H, i} * \text { Entropy }_{H K, i} & - & - & - & 19.508^{* * *} \\ \text { Adjusted R-squared }_{\text {Entr }} & 0.015 & 0.011 & 0.035 & 0.213\end{array}$

Panel B: Financial Crisis Period

$\begin{array}{ccccc} & 1 & 2 & 3 & 4 \\ \text { Intercept } & -0.138^{* * *} & -0.115^{* * *} & -0.144 * * * & 0.336^{* * *} \\ \text { Entropy }_{S H, i} & -0.144 & - & -0.099 & -0.805^{* *} \\ \text { Entropy }_{H K, i} & 1.910^{* * *} & - & 1.968^{* * *} & 0.577 \\ \left|R H O_{i}\right| & - & 1.012^{* * *} & -0.054 & -1.908^{* * *} \\ \text { Entropy }_{S H, i} *\left|R H O_{i}\right| & - & - & - & 5.537 * * * \\ \text { Entropy }_{H K, i} *\left|R H O_{i}\right| & - & - & - & 2.755^{* * *} \\ \text { Entropy }_{S H, i} * \text { Entropy }_{H K, i} & - & - & - & -2.249 \\ \text { Adjusted R-squared }_{\text {Entro }} & 0.934 & 0.757 & 0.934 & 0.984\end{array}$

Note. There are 648 and 813 observations for each variable for panel A and B, respectively.

$* \mathrm{p}<.10 . * * \mathrm{p}<.05 . * * * \mathrm{p}<.01$. 
Compared to the results based on the market composite indices, the cross-wavelet coherence

based on the cross-listing indices suggests stronger market co-movement for the sample period.

Additionally, I ran the regression models based on the new indices, ${ }^{25}$ and the results are reported in

Table 15.

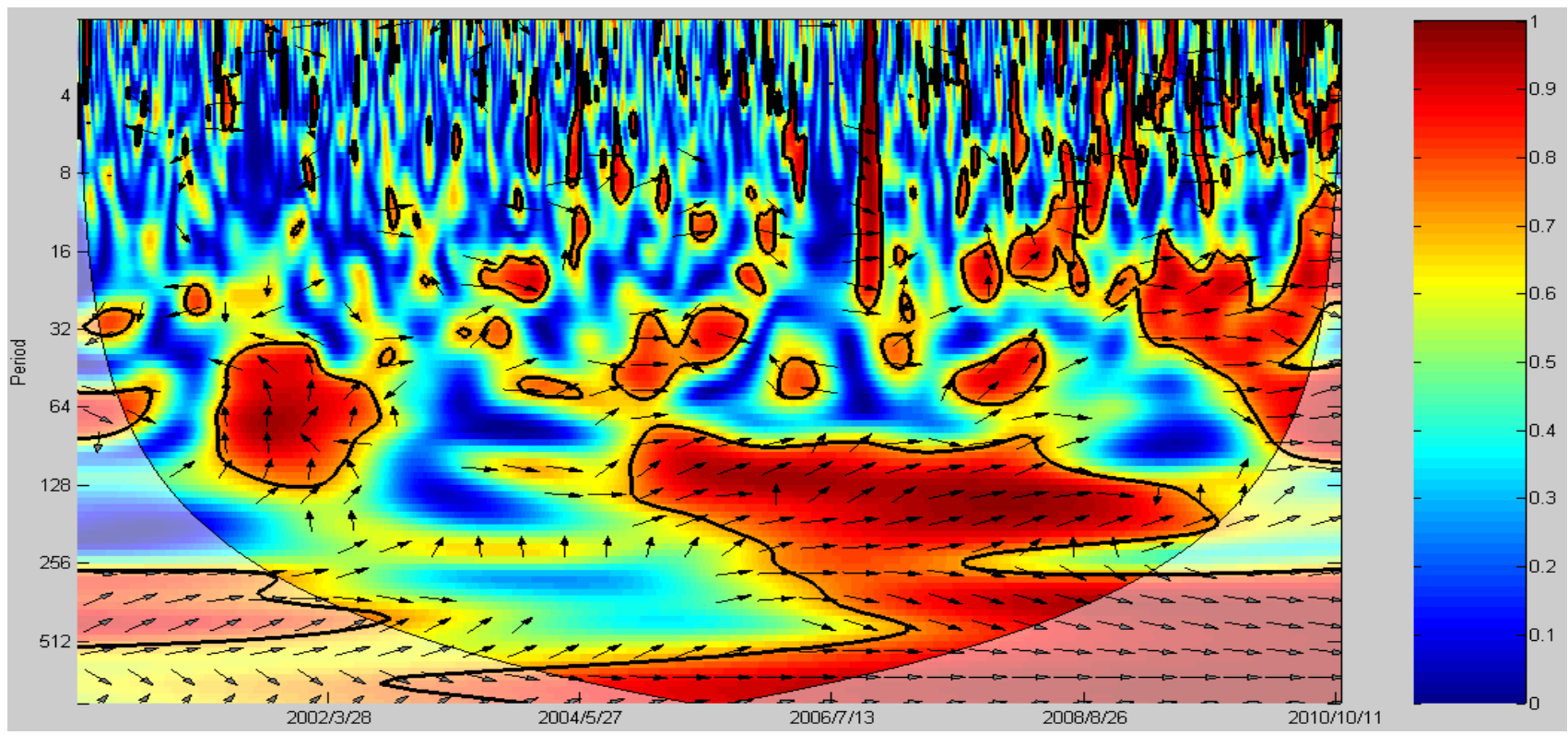

Figure 10. Wavelet Coherence between the two Markets based on Cross-Listing Indices

Note. The value of squared wavelet coherence is in the range of 0 and 1. A leftward arrow indicates a negative relationship between the two time series, and a rightward arrow implies a positive correlation. The higher the value of squared wavelet coherence, the stronger correlation between the two time series. The scale (or frequency) of analyzing is indicated by the vertical axis, while the time interval is indicated by the horizontal axis. Moreover, the bold line suggests the significance level at 5\% level, which is determined by Monte Carlo simulation of 10,000 sets of two white noise time series with the same length as the series.

\footnotetext{
${ }^{25}$ The return based on cross-listing indices is weighted by the market capitalization. The market capitalization for each composite company on a given day is computed as the product of the closing price and the total amount of the common shares issued by the company.
} 
Table 15 Relationships among Market Co-movement, Internal Market Efficiency and Cross-Market Efficiency Based on Cross-Listing Indices

Panel A: Releasing Period

$\begin{array}{ccccc} & 1 & 2 & 3 & 4 \\ \text { Intercept } & -0.144 * * * & 0.125^{* * *} & -0.209 * * * & -0.093 \\ \text { Entropy }_{S H, i} & 1.054 * * * & - & 0.879 * * * & 1.505 * * \\ \text { Entropy }_{H K, i} & 0.336^{* * *} & - & 0.487 * * * & -0.205 \\ \left|R H O_{i}\right| & - & 0.265^{* * *} & 0.273 * * * & 0.208 \\ \text { Entropy }_{S H, i} *\left|R H O_{i}\right| & - & - & - & -4.416^{* * *} \\ \text { Entropy }_{H K, i} *\left|\mathrm{RHO}_{i}\right| & - & - & - & 4.113^{* * *} \\ \text { Entropy }_{S H, i} * \text { Entropy }_{H K, i} & - & - & - & -1.181 \\ \text { Adjusted R-squared } & 0.281 & 0.305 & 0.595 & 0.674\end{array}$

Panel B: Financial Crisis Period

\begin{tabular}{|c|c|c|c|c|}
\hline & 1 & 2 & 3 & 4 \\
\hline Intercept & $-0.100 * *$ & $0.432 * * *$ & $-0.100 * *$ & $0.656 * * *$ \\
\hline Entropy $_{S H, i}$ & -0.248 & - & -0.248 & $-3.474 * * *$ \\
\hline Entropy $_{H K, i}$ & $2.055^{* * *}$ & - & $2.055^{* * *}$ & -0.047 \\
\hline$\left|R H O_{i}\right|$ & - & 0.112 & 0.000 & $-0.288 * * *$ \\
\hline Entropy $_{S H, i} *\left|R H O_{i}\right|$ & - & - & - & $2.995 * * *$ \\
\hline Entropy $_{H K, i} *\left|R H O_{i}\right|$ & - & - & - & $-2.197 * * *$ \\
\hline Entropy $_{S H, i} *$ Entropy $_{H K, i}$ & - & - & - & $9.135^{* * *}$ \\
\hline Adjusted R-squared & 0.892 & 0.019 & 0.892 & 0.926 \\
\hline
\end{tabular}

Note. There are 648 and 934 observations for each variable for panel A and B, respectively.

$* * \mathrm{p}<.05, * * * \mathrm{p}<.01$.

The results based on the cross-listing indices yield similar results as those reached based on the market composite indices. First, when examining the effect of the internal market efficiency, only the internal market efficiency of the Shanghai Exchange has a significant effect on the cross-market 
efficiency at the 5\% level, as suggested in column 4 . However, the effect varies during different periods. During the financial crisis, the improvement of the internal market efficiency of the Shanghai Exchange leads to the improvement of the cross-market efficiency. During the releasing period, the improvement of the internal market efficiency of the Shanghai Exchange deteriorated the cross-market efficiency. In terms of the effect of the market co-movement, during the financial crisis, the strengthening of the market co-movement improved the cross-market efficiency. During the releasing period, the effect of the market co-movement is negative but insignificant. In the case of the effects of the interaction terms, no matter what condition the market is in, the interaction terms have a significant effect on the cross-market efficiency.

Additionally, Generalized Method of Moments (GMM) models are manipulated to account for the non-linearity issues of measurements. The models are over-identified, and corresponding J-tests are generally insignificant at the $10 \%$ level, which suggests the selection of the instruments is valid. The results are similar as the ones in previous section and reported in Table 16. 
Table 16 GMM Regressions for Relationship among Internal Market Efficiency, Market Co-movement, and Cross-Market Efficiency

Panel A: Normal Market

$\begin{array}{ccccc} & 1 & 2 & 3 & 4 \\ \text { Intercept } & -0.035^{* *} & 0.066^{* * *} & -0.042 * * * & 0.121^{* * *} \\ \text { Entropy }_{S, i} & 0.255^{* * *} & - & 0.201 * * * & -0.556^{* * *} \\ \text { Entropy }_{H K, i} & 0.366^{* * *} & - & 0.370^{* * *} & -0.160 \\ \left|R H O_{i}\right| & - & 0.131^{* * *} & 0.130^{* * *} & -0.470 \\ \text { Entropy }_{S H, i} *\left|R H O_{i}\right| & - & - & - & 2.588^{* * *} \\ \text { Entropy }_{H K, i} *\left|\mathrm{RHO}_{i}\right| & - & - & - & 0.522 \\ \text { Entropy }_{S H} * \text { Entropy }_{H K, i} & - & - & - & 2.208 * *\end{array}$

Adjusted R-squared

0.284

0.083

0.346

0.396

Panel B: Releasing Period

$\begin{array}{ccccc} & 1 & 2 & 3 & 4 \\ \text { Intercept } & 0.023 & 0.065 * * * & 0.019 & 0.242 * * \\ \text { Entropy }_{S H, i} & 0.001 & - & -0.010 & -1.648 * * * \\ \text { Entropy }_{H K, i} & 0.318^{* * *} & - & 0.304 * * * & -0.977 \\ \left|R H O_{i}\right| & - & 0.055 & 0.057 * & 0.008 \\ \text { Entropy }_{S H, i} *\left|R H O_{i}\right| & - & - & - & 3.427 * * * \\ \text { Entropy }_{H K, i} *\left|R H O_{i}\right| & - & - & - & -4.067 * * * \\ \text { Entropy }_{S H, i} * \text { Entropy }_{H, i} & - & - & - & 9.751 * *\end{array}$

Adjusted R-squared

0.045

0.014

0.064

0.196

Panel C: Financial Crisis Period

\begin{tabular}{|c|c|c|c|c|}
\hline & 1 & 2 & 3 & 4 \\
\hline Intercept & $-0.186 * * *$ & $-0.162 * * *$ & $-0.179 * * *$ & $0.383 * * *$ \\
\hline Entropy $_{S H, i}$ & 0.077 & - & -0.009 & $-1.046 * * *$ \\
\hline Entropy $_{H K, i}$ & $1.851 * * *$ & - & $1.722 * * *$ & $0.631 * *$ \\
\hline$\left|R H O_{i}\right|$ & - & $1.189 * * *$ & $0.129 *$ & $-1.950 * * *$ \\
\hline Entropy $_{S H, i} *\left|R H O_{i}\right|$ & - & - & - & $5.697 * * *$ \\
\hline Entropy $_{H K, i} *\left|R H O_{i}\right|$ & - & - & - & $2.270 * * *$ \\
\hline Entropy $_{S H, i} *$ Entropy $_{H K, i}$ & - & - & - & $-1.544^{*}$ \\
\hline Adjusted R-squared & 0.926 & 0.752 & 0.928 & 0.979 \\
\hline
\end{tabular}

Note. There are 1407, 808, and 643 observations for each variable for panel A, B, and C, respectively. $* \mathrm{p}<.10 . * * \mathrm{p}<.05 . * * * \mathrm{p}<.01$. 


\section{Conclusion}

In this study, I delineate the market co-movement by the cross-wavelet coherence, the market efficiency by the entropy and the cross-market efficiency by the mutual information, respectively. Additionally, I examine the relationships among these three concepts in three time periods, the normal period, the releasing (normal condition market) period, and the financial crisis (extreme market) period, respectively. Based on the study, I present following conclusions:

First, the market microstructure has a significant effect on the internal market efficiency in each market. However, this effect is also affected by the external environment (such as the condition of the market) and the frequency of the change.

Second, the internal market efficiency of the advanced market is not always more efficient than that of the emerging market. This observation is not consistent with the general belief that the advanced market should be more efficient than the emerging market. There are two possible explanations. First, the measurement of entropy is to capture the predictability of returns series in the market. Hence, this study shows that the uncertainty in the Hong Kong Stock Exchange is not always greater than that in the Shanghai Stock Exchange. However, other aspects regarding the market efficiency, for example how rapid the market price converges to the effective price, are not examined in this study. Second, the observation is based on the unique setting that the Shanghai Exchange and the Hong Kong Exchange are under the same regulation of Chinese government. Thus, the results may be different from those based on American markets or European markets.

Third, the cross-market efficiency is affected by the internal market efficiency of the emerging market, but not by the market co-movement and the internal market efficiency of the developed market during normal period. On the other hand, the cross-market efficiency is determined by both the internal market efficiency of the emerging market and the market co-movement during 
the financial crisis period.

Finally, during the financial crisis period, the strengthening of the market co-movement is associated with the deterioration of the cross-market efficiency, whereas the market co-movement has no effect on the cross-market efficiency. This observation confirms Dwyer and Wallace's (1992) statement that strong market co-movement does not imply cross-market inefficiency. 


\section{References}

Alampieski, K., \& Lepone, A. (2009). Impact of a tick size reduction on liquidity: Evidence from the Sydney Futures Exchanges. Accounting and Finance, 49, 1-20. doi: 10.1111/j.1467-627x.2008.00279.x

Alexakis, C.,\& Balios, D. (2008). Investigating the effects of market microstructure on stock price formation and volatility: Evidence from the Athens Stock Exchange. Applied Financial Economics Letters, 4, 225-231. doi: 10.1080/17446540701704364

Amihud, Y., Mendelson, H., \& Uno, J. (1999). Number of shareholders and stock prices: Evidence from Japan. The Journal of Finance, 3, 1169-1184. doi: 10.1111/0022-1082.00141

Ascioglu, A., Comerton-Forde, C., \& McInish, T. H. (2010). An examination of minimum tick sizes on the Tokyo Stock Exchange. Japan and the World Economy, 22, 40-48. doi: 10.1016/j.japwor.2009.06.006

Asem, E. (2007). Concentrated opening volume: Market closure or strategic trading?. The Journal of Financial Research, 2, 321-334. doi: 10.1111/j.1475-6803.2007.00216.x

Aslanidis, N., Osborn, D. R. \& Sensier, M. (2009). Co-movements between US and UK stock prices: The role of time-varying conditional correlations. International Journal of Finance and Economics, 15, 366-380. doi: 10.1002/ijfe.402

Asmar, M. \& Ahmad, Z. (2011). Market microstructure: The components of black-box. International Journal of Economics and Finance, 1, 152-159.

Beine, M., Cosma, A., \& Vermeulen (2009). The dark side of global integration: Increasing tail dependence. Journal of Banking \& Finance, 1, 184-192. doi: 10.1016/j.jbankfin.2009.07.014

Bodart, V. \& Reding, P. (1999). Exchange rate regime, volatility and international correlations on bond and stock markets. Journal of International Money and Finance, 18, 133-151. doi: 10.1016/S0261-5606(98)00042-4

Boehmer, E., Jones, C. M., \& Zhang, X. (2008). Which shorts are informed?. The Journal of Finance, 2, 491-527. doi: 10.1111/j.1540-6261.2008.01324.x

Boehmer, E., \& Wu, J. (2009). Short selling and the informational efficiency of prices. Working paper, University of Georgia. doi: 10.1111/j.1540-6261.2008.01324.x

Booth, et al. (2002). Trading and pricing in upstairs and downstairs stock markets. The Review of Financial Studies, 4, 1111-1135. doi: 10.1093/rfs/15.4.1111

Brissaud, J. (2005).The meanings of entropy. Entropy, 7(1), 68-96.

Brockman, P., Liebenberg, I., \& Schutte M. (2010). Comovement, information production and the 
business cycle. Journal of Financial Economics, 97, 107-129. doi: 10.1016/j.jfineco.2010.03.008

Brooks, R., \& Negro (2006). Firm-level evidence on international stock market comovement. Marco. Review of Finance, 1, 69-98. doi: 10.1007/s10679-006-6979-1

Chan, S. H., Kim, K. A., \& Rhee, S. G. (2005). Price limit performance: Evidence from transactions data and the limit order book. Journal of Empirical Finance, 12, 269-290. doi: 10.1016/j.jempfin.2004.01.001

Charitou, A., \& Panayides, M. (2009). Market making in international capital markets: Challenges and benefits of its implementation in emerging markets. International Journal of Managerial Finance, 1, 50-80. doi: 10.1108/17439130932341

Chelley-Steeley, P. L. (2008). Market quality changes in the London stock market. Journal of Banking \& Finance, 32, 2248-2253. doi: 10.1016/j.jbankfin.2007.12.049

Chiang,T. C., Tan, L., \& Li, H. (2007). Empirical analysis of dynamic correlations of stock returns: Evidence from Chinese A-share and B-share market. Quantitative Finance, 6, 651-667. doi: $10.1080 / 1469768060117317$

Christoffersen, et al., (2011). Is the potential for international diversification disappearing?. Working Paper.

Chung, K. H., \& Chuwonganant, C. (2009). Transparency and market quality: Evidence from SuperMontage. Journal of Financial Intermediation, 1, 93-111.

Chung, K. H., Kang, J., \& Kim, J. (2011). Tick size, market structure, and market quality. Review of Quantitative Finance \& Accounting, 36, 57-81. doi: 10.1007/s11156-010-0171-6

Comerton-Forde, C., \& Rydge, J. (2006). The current state of Asia-Pacific Stock Exchanges: A critical review of market design. Pacific-Basin Finance, 14, 1-32. doi: 10.1016/j.pacfin.2005.05.002

Comerton-Forde, C., Rydge, J., \& Burridge H. (2007). Not all call auction are created equal: Evidence from Hong Kong. Review of Quantitative Finance \& Accounting, 4, 394-413. doi: 10.1007/s11156-007-0036-9

Crowley, P. (2005). An intuitive guide to wavelets for economists. Working Paper Series, Bank of Finland.

Darbellay, G. A., \& Wuertz, D. (2000). The entropy as a tool for analysing statistical dependences in financial time series. Physica A, 287, 429-439. doi: 10.1016/S0378-4371(00)00382-4

Demarchi, M., \& Foucault, T. (2000). Equity trading systems in Europe: A survey of recent changes. 
Annals of Economics and Statistics, 60, 1-32.

Devenow, A., \& Welch, I. (1996). Rational herding in financial economics. European Economic Review, 40, 603-615. doi: 10.1016/0014-2921(95)00073-9

Dwyer, G. P., \& Wallace, M. S. (1992). Cointegration and market efficiency. Journal of International Money and Finance, 4, 318-327. doi: 10.1016/0261-5606(92)90027-U

Easley, D., \& O'Hara, M. (1991). Order form and information in securities markets. The Journal of Finance, 3, 905-927. doi: 10.1111/j.1540-6261.1991.tb03771.x

Engel, C. (1996). A note on cointegration and international capital market efficiency. Journal of International Money and Finance, 15, 657-660. doi: 10.1016/0261-5606(96)00028-9

Gençay, R., Selçuk, F., \& Whitcher, B. (2003). Systematic risk and timescales. Quantitative Finance, 3, 108-116.

Gençay, R., Selçuk, F., \& Whitcher, B. (2005). Information flow between volatilities across time scales. Working Paper, Simon Fraser University.

Gerace, D., Tian, G., \& Zheng, W. (2009). Call auction transparency and market liquidity: The Shanghai experience. Working paper, University of Wollongong.

Grinsted, A., Moore, J. C., \& Jevrejeva S. (2004). Cross wavelet and wavelet coherence. Retrieved Sep. $1^{\text {st }} 2011$ from POL, http://www.pol.ac.uk/home/research/waveletcoherence/.

Gulko, L. (1999). The entropic market hypothesis. International Journal of Theoretical and Applied Finance, 2, 293-329. doi: 10.1142/S0219024999000170

Harris, L., \& Hasbrouck, J. (1996). Market vs. limit orders: The SuperDOT evidence on order submission strategy. The Journal of Financial and Quantitative Analysis, 31, 213-231.

Hasbrouck, J. (1993). Assessing the quality of a security market: A new approach to transaction-cost measurement. Review of Financial Studies, 6, 191-212. doi: 10.1093/rfs/6.1.191

Hauser, S., \& Lauterbach, B. (2003). The impact of minimum trading units on stock value and price volatility. Journal of Financial and Quantitative Analysis, 38, 575-589. doi: $10.2307 / 4126732$

Helder, J., \& Jin, H. (2007). Long memory in commodity futures volatility: A wavelet perspective. The Journal of Futures Markets, 27, 411-437. doi: 10.1002/fut.20260

Hey, J., \& Morone, A. (2004). Do markets drive out lemmings - or vice versa?. Economica, 71, 284, 637-659. doi: 10.1111/j.0013-0427.2004.00392.x 
HKEx (May 31, 2011). A glimpse of the past. Retrieved Sep. $1^{\text {st }} 2011$ from HKEx Ltd., http://www.hkex.com.hk/eng/exchange/corpinfo/history/history.htm.

Hou, K., \& Moskowitz, T. J. (2005). Market frictions, price delay, and the cross-section of expected returns. Review of Financial Studies, 18, 981-1020. doi: 10.1093/rfs/hhi023

Hsieh, T., Chuang, S., \& Lin, C. (2008). Impact of tick-size reduction on the market liquidity Evidence from the emerging order-driven market. Review of Pacific Basin Financial Markets \& Policies, 11, 591-616.

Huang, R. D., \& Stoll, H. R. (1996). Dealer versus auction markets: A paired comparison of execution costs on NASDAQ and the NYSE. Journal of Financial Economics, 41, 313-357. doi: 10.1016/0304-405X(95)00867-E

Janosi, T., Jarrow, R., \& Zullo F. (1999).An empirical analysis of the Jarrow-Van Deventer Model for valuing non-maturity demand deposits. Journal of Derivatives, 7, 8-31. doi: 10.3905/jod.1999.319107

Kanas, A. (2002). Is exchange rate volatility influenced by stock return volatility? Evidence from the US, UK and Japan. Applied Economics Letters, 9, 501-03. doi: 10.1080/13504850110095783

Kühl, M. (2010). Bivariate cointegration of major exchange rates, cross-market efficiency and the introduction of the Euro. Journal of Economics and Business, 62, 1-19. doi: 10.1016/j.jeconbus.2009.07.002

Kurov, A. (2008). Tick size reduction, execution costs, and informational efficiency in the regular and e-mini NASDAQ-100 Index futures markets. The Journal of Futures Markets, 28, 871-888. doi: 10.1002/fut.20341

Lagoarde-Segot, T. (2009). Financial reforms and time-varying microstructure in emerging equity markets. Journal of Banking \& Finance, 33, 1755-1769. doi: 10.1016/j.jbankfin.2009.01.007

Lence, S. \& Falk, B. (2005). Cointegration, market integration, and market efficiency. Journal of International Money and Finance, 24, 873-890. doi: 10.1016/j.jimonfin.2005.05.002

Lepone, A., \& Yang, J. (2010). The impact of off-market trading on liquidity: Evidence from the Australian options market. The Journal of Futures Markets, 30, 361-377. doi: $10.1002 /$ fut. 20428

Madhavan, A. (1992). Trading mechanisms in securities markets. The Journal of Finance, 2, 607-641. doi: 10.1111/j.1540-6261.1992.tb04403.x

Madhavan, A. (2000). Market microstructure: A survey. Working Paper, University of Southern California. 
Madhavan, A., Porter, D., \& Weaver, D. (2005). Should securities markets be transparent?. Journal of Financial Markets, 8, 265-287.

Maraun, D., \& Kurths, J. (2004). Cross wavelet analysis: Significance testing and pitfalls. Nonlinear Processes in Geophysics, 11, 505-514. doi: 10.5194/npg-11-505-2004

Masset, P. (2008). Analysis of financial time-series using Fourier and wavelet methods. Working Paper, University of Fribourg (Switzerland).

Morck, R., Yeung, B., \& Yu W. (2000). The information content of stock markets: Why do emerging markets have synchronous stock price movements?. Journal of Financial Economics, 58, 215-260.

Mucklow, B. (1994). Market microstructure: An examination of the effects on intraday event studies. Contemporary Accounting Research, 10, 355-382. doi: 10.1111/j.1911-3846.1994.tb00397.x

Nielsen, M., \& Frederiksen, P. (2005). Finite sample comparison of parametric, semiparametric, and wavelet estimators of fractional integration. Econometric Reviews, 24, 405-443. doi: $10.1080 / 07474930500405790$

O’Hara, M. (1995). Market microstructure theory. Basil Blackwell, Cambridge, Mass.

Pagano, M., \& Roell, A. (1996). Transparency and liquidity: A comparison of auction and dealer markets with informed trading. The Journal of Finance, 51, 579-611. doi: 10.1111/j.1540-6261.1996.tb02695.x

Pagano, M., \& Schwartz, R. (2003). A closing call's impact on market quality at Euronext Paris. Journal of Financial Economics, 68, 439-484. doi: 10.1016/S0304-405X(03)00073-4

Pavabutr, P. and S. Prangwattananon (2008). Tick size change on the stock exchange of Thailand. Review of Quantitative Finance and Accounting, 32, 351-371. doi: 10.1007/s11156-008-0096-5

Pele, D., \& Tepus, A. (2011). Information entropy and efficient market hypothesis. International Conference on Applied Economics, 463-472.

Peng, H. (2007). Mutual information computation. Retrieved Dec. 2011 from Matlab Central: http://www.mathworks.com/matlabcentral/fileexchange/14888.

Phylaktis, K., \& Xia, L. (2009). Equity market comovement and contagion: A sectoral perspective. Financial Management, 381-409.

Roosenboom, P., \& Dijk, M. A. (2009). The market reaction to cross-listing: Does the destination market matter?. Journal of Banking \& Finance, 33, 1898-1908. doi: 10.1016/j.jbankfin.2009.04.010 
Rua, A., \& Nunes, L. C. (2009). International comovement of stock market returns: A wavelet analysis. Journal of Empirical Finance, 16, 632-639. doi: 10.1016/j.jempfin.2009.02.002

Ryoo, H., \& Graham, S. (2002). Korean stock prices under price limits: Variance ratio tests of random walks. Applied Financial Economics, 12, 545-553. doi: 10.1080/09603100010015789

Sinnakkannu, J., \& A. Md Nassir, (2006). Market microstructure changes and time to equilibrium (TTE)? Evidence Bursa Malaysia. International Research Journal of Finance and Economics, 6, 31-48.

Subbotin, A. (2008). A multi-horizon scale for volatility. Working Paper Series, University of Paris-1.

Torrence, C., \& Compo, G. (1998). A practical guide to wavelet analysis. Bulletin of American Meteorological Society, $\quad 79, \quad 61-78 . \quad$ doi: 10.1175/1520-0477(1998)079<0061:APGTWA>2.0.CO;2

Torrence, C., \& Webster, P. (1998). The annual cycle of persistence in the El Niño southern oscillation. Quarterly Journal of the Royal Meteorological Society, 124, 550, 1985-2004. doi: 10.1002/qj.49712455010

Xu, C. K. (2000). The microstructure of the Chinese stock market. China Economic Review, 11, 79-97. doi: 10.1016/S1043-951X(99)00013-9

Zunino, et al. (2009). Forbidden patterns, permutation entropy and stock market inefficiency. Physica A, 388, 2854-2864. doi: 10.1016/j.physa.2009.03.042 